\title{
TP53 mutations and protein immunopositivity may predict for poor outcome but also for trastuzumab benefit in patients with early breast cancer treated in the adjuvant setting
}

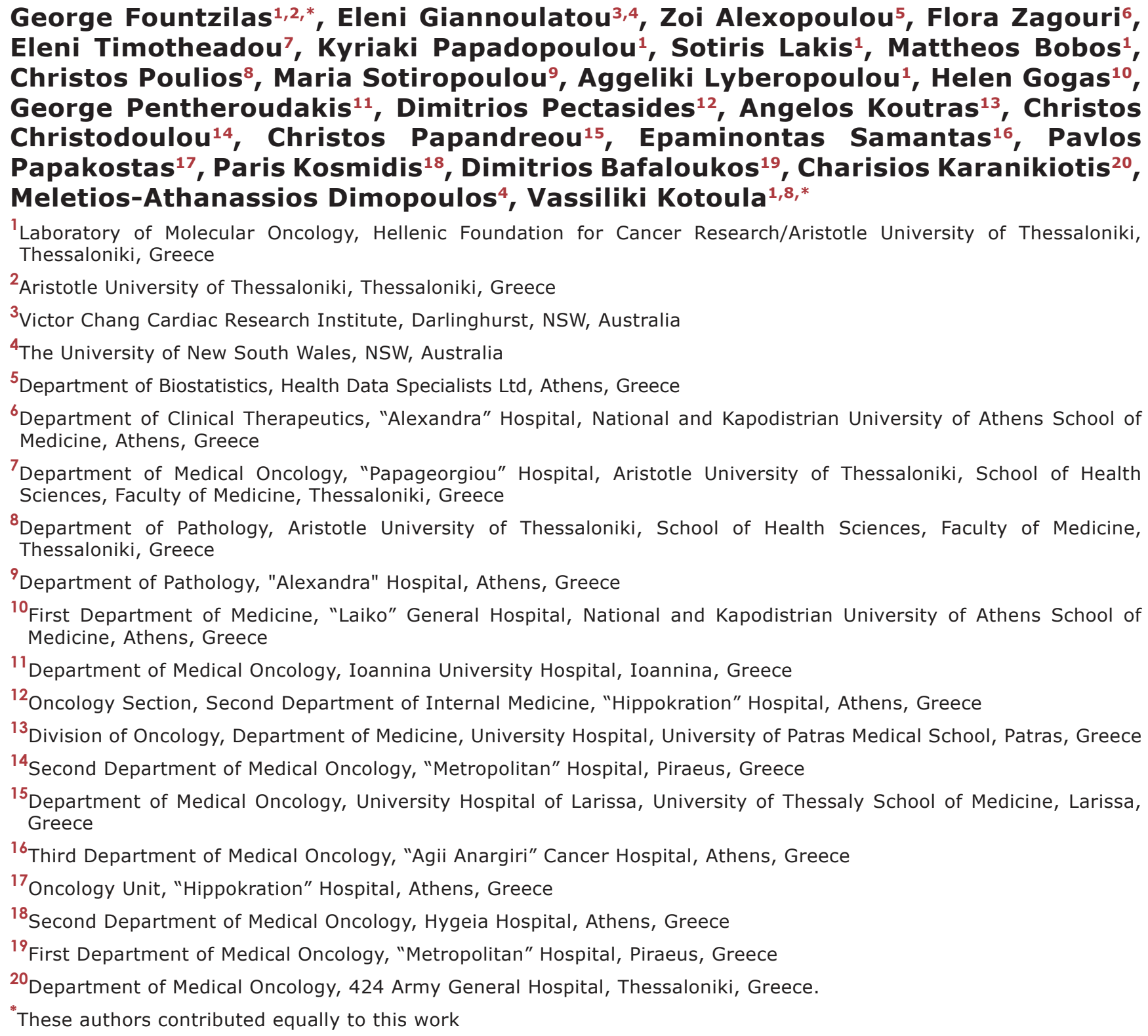

\section{ABSTRACT}

Background: We investigated the impact of PIK3CA and TP53 mutations and p53 protein status on the outcome of patients who had been treated with adjuvant anthracycline-taxane chemotherapy within clinical trials in the pre- and post-trastuzumab era. 
Results: TP53 and PIK3CA mutations were found in $380(21.5 \%)$ and 458 (25.9\%) cases, respectively, including 104 (5.9\%) co-mutated tumors; p53 immunopositivity was observed in 848 tumors $(53.5 \%)$. TP53 mutations $(p<0.001)$ and p53 protein positivity $(p=0.001)$ were more frequent in HER2-positive and triple negative (TNBC) tumors, while PIK3CA mutations were more frequent in Luminal A/B tumors $(p<0.001)$. TP53 mutation status and p53 protein expression but not PIK3CA mutation status interacted with trastuzumab treatment for disease-free survival; patients with tumors bearing TP53 mutations or immunopositive for p53 protein fared better when treated with trastuzumab, while among patients treated with trastuzumab those with the above characteristics fared best (interaction $p=0.017$ for mutations; $p=0.015$ for IHC). Upon multivariate analysis the above interactions remained significant in HER2-positive patients; in the entire cohort, TP53 mutations were unfavorable in patients with Luminal A/B $(p=0.003)$ and TNBC $(p=0.025)$; p53 immunopositivity was strongly favorable in patients treated with trastuzumab $(p=0.009)$.

Materials and Methods: TP53 and PIK3CA mutation status was examined in 1766 paraffin tumor DNA samples with informative semiconductor sequencing results. Among these, 1585 cases were also informative for p53 protein status assessed by immunohistochemistry (IHC; $10 \%$ positivity cut-off).

Conclusions: TP53 mutations confer unfavorable prognosis in patients with Luminal A/B and TNBC tumors, while p53 immunopositivity may predict for trastuzumab benefit in the adjuvant setting.

\section{INTRODUCTION}

Breast cancer is the most common malignancy and the leading cause of death from cancer among women worldwide [1]. It is estimated that during 2015 approximately 232,000 new cases will be diagnosed and 40,000 deaths will occur in the US [2].

In almost all randomized trials that evaluated different agents or combinations in the adjuvant setting in the past decades, breast cancer was treated as a single clinical entity in terms of chemotherapy; tumor biological characteristics that were addressed for additional targeted drugs were positivity for hormone receptors $(\mathrm{ER} / \mathrm{PgR})$ and later on, HER2 protein overexpression / gene amplification. Eventually, however, following initial molecular subtyping [3-5], researchers realized that breast cancer is a heterogeneous group of diseases, displaying distinct biology, responses to various treatments and clinical outcomes [6]. Recently, whole genome and exome sequencing studies have contributed to a wealth of genomic and comprehensive molecular alteration data for almost every type of cancer, including breast cancer [7], providing an unprecedented view to the inter- and intra-tumoral heterogeneity of these malignancies [8]. Ultimately, the major incentive for investigating the impact of (somatic) mutations in tumor behavior is the potential for the development of effective targeted anticancer treatments. Unfortunately, the technology needed for the above impressive achievements is not easily applicable in large trials, since it is costly and requires fresh-frozen tissue, which is mostly not available. To overcome these hurdles, investigators have been increasingly adapting methods and markers for application on formalin-fixed paraffin-embedded (FFPE) tumor tissues [9].

As revealed in whole genome and exome studies, PIK3CA and TP53 are by far the most commonly mutated genes in breast cancer $[10,11]$. The tumor suppressor TP53 gene [12], located on the short arm of chromosome 17 (17p13.1), is mutated in approximately $30 \%$ of breast cancers [13]. Even though over 4,300 different TP53 mutations have been reported in patients with cancer, novel mutations are continuously being identified [14], while mutation rates between intrinsic or immunophenotypical tumor subtypes vary $[10,15]$. Most somatic TP53 mutations are located in the region coding for the DNA binding domain (DBD) of the protein [16]. TP53 mutations are associated with bad prognosis in breast cancer, whereby the position and type of mutation may be important for patient outcome (reviewed in [17, 18]). TP53 mutations are characterized as loss-of-function or gain-offunction but the result of practically all TP53 mutations is stabilization of the mutant protein [19]. The shortlived wild-type p53 protein [20] is unnoticed in surgical specimens with immunohistochemistry, but the stabilized mutant protein accumulates and can be demonstrated, provided that the detector antibody can bind to the mutant epitope. Of note, nuclear $\mathrm{p} 53$ protein accumulation, which only partially reflects TP53 mutation status, as shown in earlier studies [21, 22], was also reported to adversely impact breast cancer patient outcome [23-25].

The phosphatidylinositol-4,5-bisphosphonate 3-kinase catalytic subunit alpha (PIK3CA) gene, located 
in the long arm of chromosome 3 (3q26.32), is mutated in approximately $27 \%$ of breast carcinomas [26]. PIK3CA mutations are reported to cluster within the helical domain (exon 10; coding exon 9) and the kinase domain (exon 21, coding exon 20) [27]. Importantly, PIK3CA mutations have been associated with favorable clinicopathological parameters, i.e. ER expression, smaller tumor size and low histological grade, as well as good prognosis [28, 29].

Even though the prognostic/predictive role of TP53 and PIK3CA mutations has been addressed in a considerable number of studies, information regarding their role with respect to specific breast cancer subtypes within the context of adjuvant trials remains limited. Our Group has recently initiated a large study evaluating the impact of tumor mutation patterns on breast cancer patient outcome with respect to clinical subtypes and treatment. FFPE tumor DNA from patients participating in four adjuvant trials conducted by our Group, was sequenced for a panel of gene targets based on the incidence of previously identified recurrently mutated genes in breast cancer $[10,11,30]$. Herein, we present our findings on TP53 and PIK3CA mutations. In addition, because of the above cited possible unfavorable prognostic effect of p53 protein immunopositivity in good prognosis breast cancer $[23,24]$, we compared this marker with TP53 mutations, as well.

\section{RESULTS}

\section{Distribution of TP53 and PIK3CA mutations in tumor tissues}

Mutations were considered for amino acid changing variants in coding regions with minor allele frequency $(\mathrm{MAF})<0.1 \%$ in the case of registered single nucleotide polymorphisms (SNPs). For PIK3CA, 512 amino acid changing variants were mutations and for TP53 440. The majority of mutations were missense for both genes; frameshift indels occurred in PIK3CA as well, while nonsense mutations were significantly more frequent in TP53 (49/440) than in PIK3CA (6/512), in line with the tumor suppressor and oncogenic nature of these genes, respectively (Figure 1). TP53 mutations were mostly found in the coding region corresponding to the DNA binding domain (DBD) of the protein, followed by mutations in the oligomerization and the the transactivation (TAD) domains; mutations were present almost throughout the TP53 coding region except for the MDM2-binding domain, which was remarkably spared (Figure 1A). As per panel design, PIK3CA mutations were detected in the coding region corresponding to the helical and kinase domains of the protein, with similar frequency (Figure 1B). PIK3CA mutations were mostly present at the three hot-spot codons (70 tumors carried
p.Glu542; 120 p.Glu545; > 150 p.His1047). For TP53, 272 different mutations were observed; out of these, p.Arg175, p.Arg248 and p.Arg273 were observed in 15,19 and 28 patients, respectively (total $n=60$ ). All these mutated arginines were of mild to intermediate pathogenicity, located in the DBD domain, and reported within the Li-Fraumeni syndrome (NCBI, ClinVar database). The remaining TP53 mutated codons were affected in less than 10 cases each.

Mutations in either gene were found in 734 out of 1766 tumors with informative results (41.6\%); 458 tumors $(25.9 \%)$ had PIK3CA and $380(21.5 \%)$ had TP53 mutations, corresponding to $62.4 \%$ and $51.8 \%$ of mutant tumors, respectively. The two genes were co-mutated in 104 cases (5.9\% of all, $14.2 \%$ of mutant tumors). In 43 and 37 tumors more than one mutations were observed in PIK3CA and TP53, respectively. All TP53 and PIK3CA mutation data have been made publicly available at: http://www.hecog-images.gr/4adj/ngs/.

\section{Mutant TP53 and PIK3CA tumor phenotypes}

Luminal A and Luminal B tumors were examined as one group for the purposes of the present study, mainly because the concordance of defining these two subtypes with Ki67 immunohistochemistry (IHC) and with the PAM50 classifier is reported as low [31]. As expected [10], PIK3CA mutations were more common in Luminal A/B, overall in ER/PgR-positive and nonbasal as compared to HER2-positive and TNBC, overall ER/PgR-negative and basal-like tumors; TP53 mutations were more common in HER2-positive and TNBC but infrequent in Luminal A/B, and similarly more common in ER/PgR-negative and basal-like tumors (Figure 2, Table S1). The distribution of TP53 mutation types was also subtype specific with more frameshift indels and nonsense mutations in TNBC, ER/PgR-negative and basal-like tumors, but these numbers per category were very small. The observed frameshifts in PIK3CA were not related to subtypes and ER/PgR positivity. Domainspecific mutations in both genes were also subtype- and ER/PgR-specific, whereby all tumor subtypes related to $\mathrm{ER} / \mathrm{PgR}$ positivity were significantly more frequently mutated in the TP53 DNA binding domain than in the TAD and oligomerization domains; subtypes related to $\mathrm{ER} / \mathrm{PgR}$ absence more frequently had more mutations in the helical than in the transactivation domain of the PIK3CA gene.

In line with the above mutation patterns concerning ER/PgR positivity, PIK3CA mutations were significantly more frequent in grade I tumors as compared to higher tumor grades; were frequent in lobular but rare in medullary carcinomas; and, were found in low proliferating tumors (Table S1). By contrast, TP53 mutations were detected with increasing frequency from grade I to II to III tumors; were rare in 
lobular but present in almost all medullary carcinomas; were positively associated with higher CEN17 median copies.

p53 immunopositivity was noticed in 848 of 1585 evaluable tumors $(53.5 \%)$, followed the subtypespecific pattern of TP53 mutations $(p=0.001)$ and was positively associated with younger patient age ( $p=$ $0.009)$, basal phenotype $(p=0.029)$ and Ki67 labeling $(p<0.001)$.

The presence of TP53 mutations was strongly associated with p53 immunopositivity $(p<0.001)$ but the overall concordance between the two parameters was poor $($ Kappa $=0.18$; Table S3). TP53 mutations were associated with p53 immunopositivity at a rate of $74.4 \%$, which was higher for DNA binding domain (81\%) and especially missense $(89.7 \%)$ mutations; however, only half of p53 positive tumors carried TP53 mutations. Sixty-six percent of nonsense and frameshift mutations, generally prediciting for loss-of-function, were associated with negative p53 protein expression; again, the rate of such mutations within all p53 negative tumors was only $9.2 \%$.
The same pattern was observed for all major subtypes. These findings show that tumors with TP53 mutations are likely to be immunopositive for $\mathrm{p} 53$ protein but that $\mathrm{p} 53$ protein status does not predict for the presence of TP53 mutations, without any subtype specificity. A marginal association between p53 immunopositivity and PIK3CA mutation presence was also noticed $(p=0.046)$ (Table S3), with $52 \%$ of all PIK3CA, and $56 \%$ of PIK3CA missense mutant tumors demonstrating positive p53 protein status.

\section{TP53 mutations, PIK3CA mutations and p53 protein status affect disease-free survival (DFS)}

Complete follow-up and mutation data were available for 1764 patients, with 3-year and 5-year DFS rates of $88.0 \%$ and $82.2 \%$, respectively (Table 1); corresponding data were available for 1585 patients with informative p53 IHC, with 3-year and 5-year DFS rates of $88.3 \%$ and $82.8 \%$, respectively.

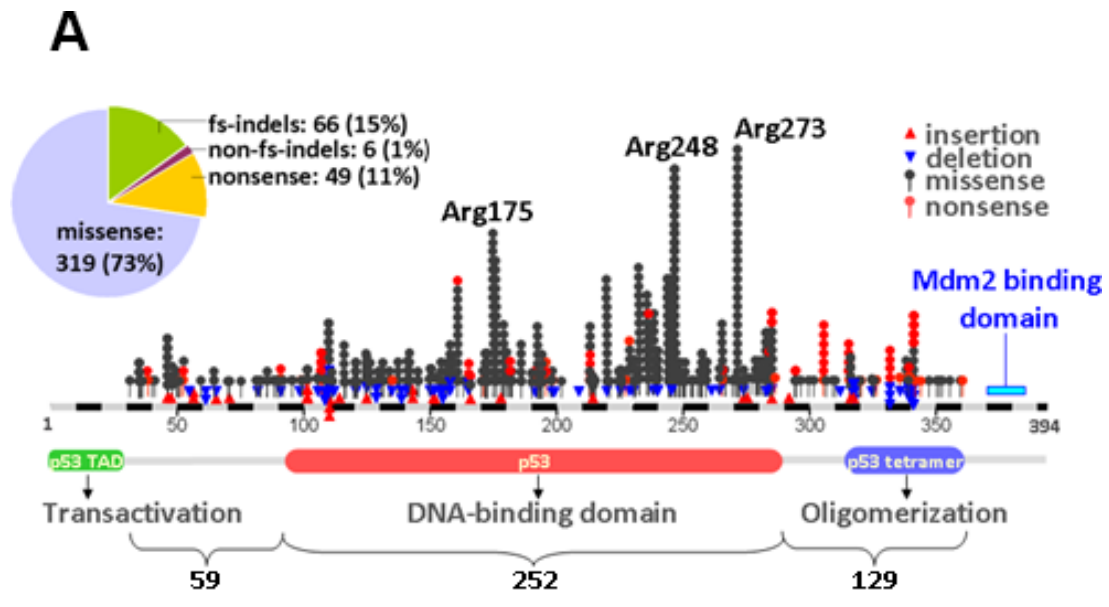

B

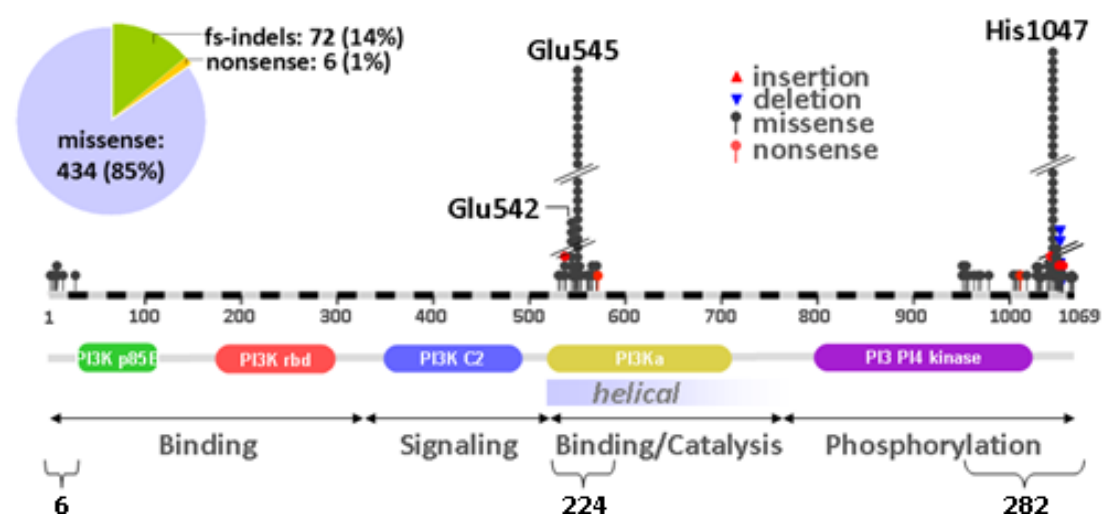

Figure 1: Distribution of TP53 and PIK3CA mutations in early breast cancer. (A) TP53 mutations were dispersed throughout the coding region but aggregated in the area coding for the DNA binding domain of the protein. (B) PIK3CA mutations were more common in the kinase domain. In the pies in A and B, the distribution of mutation types per gene is shown. fs: frameshift; indels: insertions/deletions. 
Univariate Cox results for all mutation and IHC markers with respect to patient DFS are shown in Table 2. Among the 1784 patients with informative NGS data, patients with TP53 mutations had statistically significantly worse DFS $(\mathrm{HR}=1.34 ; 95 \%$ CI $1.07-$ $1.68 ; p=0.011)$. Among the three main subtypes, TP53 mutations were strongly unfavorable in patients with Luminal A/B tumors, which constituted the largest subgroup, albeit with the lowest rate of this genomic alteration in the entire cohort (Figure 3A) and marginally unfavorable in patients with TNBC (Figure 3B). Grouping of Luminal A/B tumors for mutation analyses was justified by the lack of interaction between TP53 mutations and these two subtypes, when examined separately (Table S4). By contrast, HER2positive patients with TP53 mutant tumors showed a

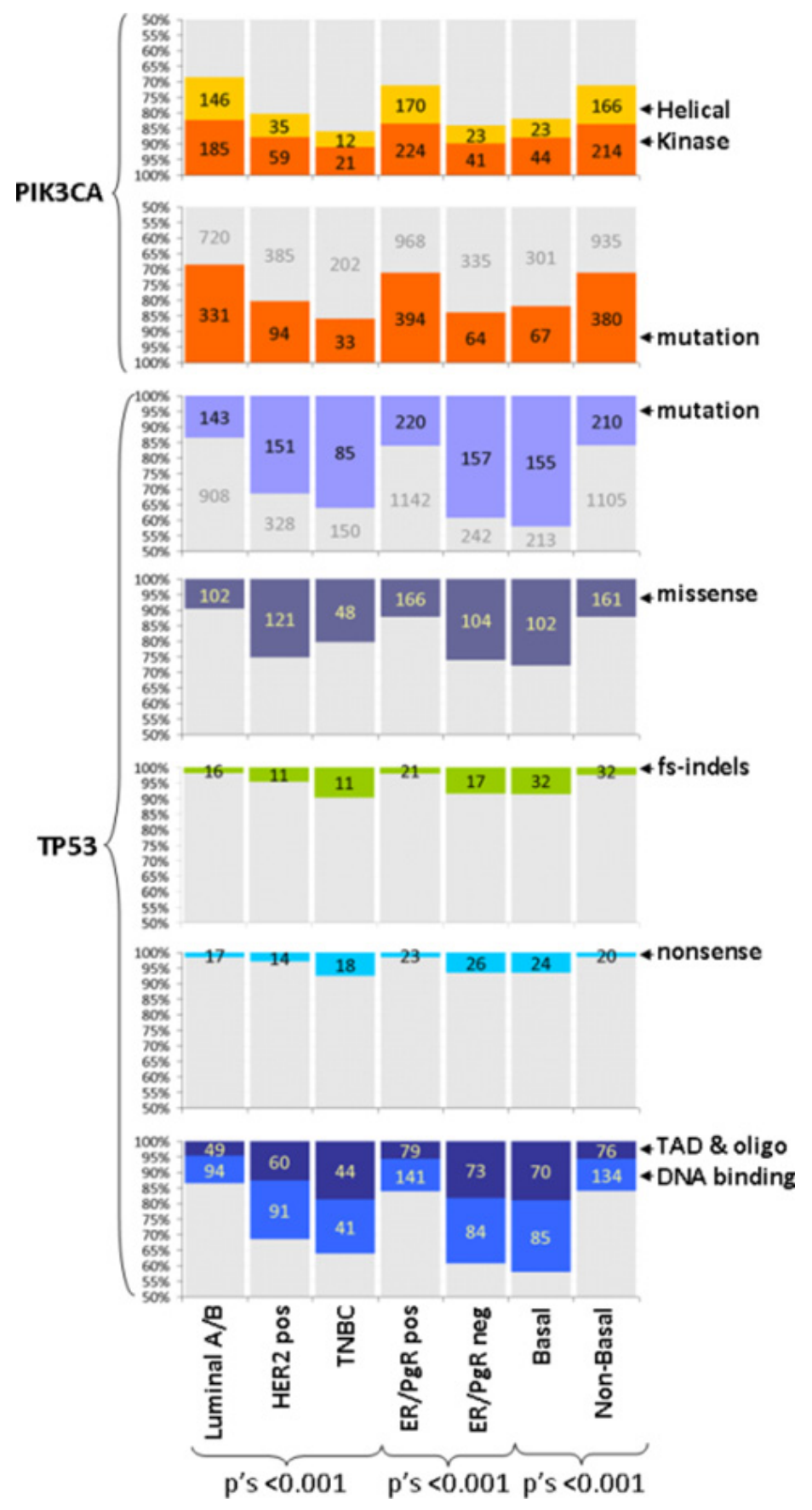

Figure 2: TP53 and PIK3CA mutation characteristics according to tumor subtypes. Mutations are described for presence / absence and domain specificity as indicated. TP53 mutations are compared for mutation types (missense, frameshift indels, nonsense). Y-axes have been truncated at 50\%. Numbers per category are shown. Grey parts in bars: complementary to the colored category. All mutations and their characteristics were related to ER/PgR status. Helical, kinase: mutations in the corresponding domains of PIK3CA; fs-indels: frameshift insertions / deletions; TAD, oligo: TP53 transactivation and oligomerization domains. 
Table 1: Patient demographics and clinicopathological parameters in the entire cohort and broken down into pre- and post-trastuzumab era trials

Trial

\begin{tabular}{cccc}
\hline Entire population & $\begin{array}{c}\text { Pre-trastuzumab } \\
\text { era trials (HE10/97 } \\
\text { and HE10/00) }\end{array}$ & $\begin{array}{c}\text { Post-trastuzumab } \\
\text { era trials (HE10/05 } \\
\text { and HE10/08) }\end{array}$ & $p$-value* \\
\hline & & &
\end{tabular}

\begin{tabular}{|c|c|c|c|c|}
\hline \multicolumn{5}{|l|}{ Patients } \\
\hline$N$ & 1766 & 620 & 1.146 & \\
\hline \multicolumn{5}{|l|}{ Age (years) } \\
\hline Mean (SD) & $53.2(11.5)$ & $52.8(11.2)$ & $53.4(11.7)$ & 0.31 \\
\hline Median & 52.9 & 52.4 & 53.3 & \\
\hline Min-Max & $21-83$ & $22-79$ & $21-83$ & \\
\hline \multicolumn{5}{|l|}{ Tumor size in $\mathrm{cm}$} \\
\hline Mean (SD) & $2.9(1.6)$ & $3.3(1.8)$ & $2.7(1.5)$ & $<0.001$ \\
\hline Median & 2.5 & 3 & 2.4 & \\
\hline Min-Max & $0-15$ & $0-15$ & $0-11$ & \\
\hline \multicolumn{5}{|c|}{ Positive lymph nodes $(N)$} \\
\hline Mean (SD) & $4.8(6.4)$ & $6.8(6.9)$ & $3.7(5.9)$ & $<0.001$ \\
\hline Median & 2 & 4 & 2 & \\
\hline Min-Max & $0-54$ & $0-43$ & $0-54$ & \\
\hline \multicolumn{5}{|c|}{ Ki67 (\% of positive cells) } \\
\hline Mean (SD) & $30.2(26.7)$ & $31.4(23.7)$ & $29.4(28.3)$ & $<0.001$ \\
\hline Median & 20 & 25 & 19.5 & \\
\hline Min-Max & $0-100$ & $0-98$ & $0-100$ & \\
\hline \multicolumn{5}{|l|}{ CEN17 copies $(N)$} \\
\hline Mean (SD) & $2.4(1.4)$ & $2.6(1.9)$ & $2.3(1.0)$ & 0.007 \\
\hline Median & 2 & 2.1 & 2 & \\
\hline \multirow[t]{2}{*}{ Min-Max } & $1-18$ & $1-18$ & $1-11$ & \\
\hline & $N(\%)$ & $N(\%)$ & $N(\%)$ & \\
\hline \multicolumn{5}{|l|}{$\operatorname{Age}(N=1764)$} \\
\hline$\leq 50$ years & $724(41.0)$ & $270(43.5)$ & $454(39.7)$ & 0.12 \\
\hline$>50$ years & $1040(59.0)$ & $350(56.5)$ & $690(60.3)$ & \\
\hline \multicolumn{5}{|c|}{ Menopausal status $(N=1764)$} \\
\hline Postmenopausal & $952(54.0)$ & $325(52.4)$ & $627(54.8)$ & 0.34 \\
\hline Premenopausal & $812(46.0)$ & $295(47.6)$ & $517(45.2)$ & \\
\hline \multicolumn{5}{|c|}{ Tumor size $(N=1763)$} \\
\hline$\leq 2 \mathrm{~cm}$ & $639(36.2)$ & $174(28.1)$ & $465(40.6)$ & $<0.001$ \\
\hline$>2 \mathrm{~cm}$ & $1124(63.8)$ & $445(71.9)$ & $679(59.4)$ & \\
\hline \multicolumn{5}{|c|}{ Positive lymph nodes $(N=1764)$} \\
\hline $0-3$ & $1057(59.9)$ & $253(40.8)$ & $804(70.3)$ & $<0.001$ \\
\hline$\geq 4$ & $707(40.1)$ & $367(59.2)$ & $340(29.7)$ & \\
\hline \multicolumn{5}{|c|}{ Histological grade $(N=1757)$} \\
\hline I & $113(6.4)$ & $29(4.7)$ & $84(7.4)$ & 0.083 \\
\hline
\end{tabular}




\begin{tabular}{|c|c|c|c|c|}
\hline II & $792(45.1)$ & $282(45.5)$ & $510(44.9)$ & \\
\hline III-Undifferentiated & $852(48.5)$ & $309(49.8)$ & $543(47.8)$ & \\
\hline \multicolumn{5}{|c|}{ Histological type $(N=1764)$} \\
\hline IC-NST & $1442(81.7)$ & $472(76.1)$ & $970(84.8)$ & $<0.001$ \\
\hline Invasive lobular & $157(8.9)$ & $60(9.7)$ & $97(8.5)$ & \\
\hline Mixed & $83(4.6)$ & $48(7.7)$ & $35(3.1)$ & \\
\hline Other & $82(4.6)$ & $40(6.5)$ & $42(3.7)$ & \\
\hline \multicolumn{5}{|c|}{ Surgery (binary) $(N=1764)$} \\
\hline MRM & $1009(57.2)$ & $428(69.0)$ & $581(50.8)$ & $<0.001$ \\
\hline Other & $755(42.8)$ & $192(31.0)$ & $563(49.2)$ & \\
\hline \multicolumn{5}{|c|}{ Hormonotherapy $(N=1759)$} \\
\hline No & $403(22.9)$ & $121(19.6)$ & $282(24.7)$ & 0.017 \\
\hline Yes & $1356(77.1)$ & $495(80.4)$ & $861(75.3)$ & \\
\hline \multicolumn{5}{|c|}{ Radiotherapy $(N=1716)$} \\
\hline No & $414(24.1)$ & $128(21.4)$ & $286(25.6)$ & 0.058 \\
\hline Yes & $1302(75.9)$ & $469(78.6)$ & $833(72.4)$ & \\
\hline \multicolumn{5}{|c|}{ Subtypes entire cohort $(N=1765)$} \\
\hline Luminal A & $588(33.3)$ & $148(23.9)$ & $440(38.4)$ & $<0.001$ \\
\hline Luminal B & $463(26.2)$ & $179(28.9)$ & $284(24.8)$ & \\
\hline Luminal-HER2 & $318(18.0)$ & $142(23.9)$ & $176(15.4)$ & \\
\hline HER2-Enriched & $161(9.1)$ & $59(9.5)$ & $102(8.9)$ & \\
\hline TNBC & $235(13.3)$ & $92(14.8)$ & $143(12.5)$ & \\
\hline \multicolumn{5}{|c|}{$\begin{array}{l}\text { Subtypes entire cohort combined } \\
(N=1765)\end{array}$} \\
\hline Luminal A/B & $1051(59.6)$ & $327(52.8)$ & $724(63.2)$ & $<0.001$ \\
\hline HER2-positive & $235(13.3)$ & $92(14.8)$ & $143(12.5)$ & \\
\hline TNBC & $479(27.1)$ & $201(32.4)$ & $278(24.3)$ & \\
\hline \multicolumn{5}{|c|}{ Subtypes concordant $(N=1248)$} \\
\hline Luminal A & $506(40.5)$ & $121(31.5)$ & $385(44.6)$ & $<0.001$ \\
\hline Luminal B & $388(31.1)$ & $141(36.7)$ & $247(28.6)$ & \\
\hline Luminal-HER2 & $150(12.0)$ & $55(14.3)$ & $95(11.0)$ & \\
\hline HER2-Enriched & $91(7.3)$ & $32(8.3)$ & $59(6.8)$ & \\
\hline TNBC & $113(9.1)$ & $35(9.1)$ & $78(9.0)$ & \\
\hline \multicolumn{5}{|c|}{$\begin{array}{l}\text { Subtypes concordant combined } \\
(N=1248)\end{array}$} \\
\hline Luminal A/B & $894(71.6)$ & $262(68.2)$ & $632(73.1)$ & 0.13 \\
\hline HER2-positive & $241(19.3)$ & $87(22.7)$ & $154(17.8)$ & \\
\hline TNBC & $113(9.1)$ & $35(9.1)$ & $78(9.0)$ & \\
\hline \multicolumn{5}{|c|}{ ER/PgR central $(N=1697)$} \\
\hline Negative & $312(18.4)$ & $115(19.6)$ & $197(17.8)$ & 0.36 \\
\hline Positive & $1385(81.6)$ & $473(80.4)$ & $912(82.2)$ & \\
\hline \multicolumn{5}{|c|}{ ER/PgR local $(N=1761)$} \\
\hline Negative & $399(22.7)$ & $151(24.4)$ & $248(21.7)$ & 0.19 \\
\hline
\end{tabular}




\begin{tabular}{|c|c|c|c|c|}
\hline Positive & $1362(77.3)$ & $467(75.6)$ & $895(78.3)$ & \\
\hline \multicolumn{5}{|c|}{ HER2 IHC central $(N=1692)$} \\
\hline No overexpression & $1459(86.2)$ & $502(84.5)$ & $957(87.2)$ & 0.13 \\
\hline Overexpression & $233(13.8)$ & $92(15.5)$ & $141(12.8)$ & \\
\hline \multicolumn{5}{|c|}{ HER2 IHC local $(N=1729)$} \\
\hline No overexpression & $1256(72.6)$ & $396(67.1)$ & $860(75.5)$ & $<0.001$ \\
\hline Overexpression & $473(27.4)$ & $194(32.9)$ & $279(24.5)$ & \\
\hline \multicolumn{5}{|c|}{ HER2 status central $(N=1707)$} \\
\hline Negative & $1305(76.4)$ & $444(74.1)$ & $861(77.7)$ & 0.096 \\
\hline Positive & $402(23.6)$ & $155(25.9)$ & $247(22.3)$ & \\
\hline \multicolumn{5}{|l|}{ CK5 central $(N=1689)$} \\
\hline Negative & $1452(86.0)$ & $523(89.7)$ & $929(84.0)$ & 0.001 \\
\hline Positive & $237(14.0)$ & $60(10.3)$ & $177(16.0)$ & \\
\hline \multicolumn{5}{|l|}{ EGFR central $(N=1690)$} \\
\hline Negative & $1404(83.1)$ & $487(83.4)$ & $917(82.9)$ & 0.80 \\
\hline Positive & $286(16.9)$ & $97(16.6)$ & $189(17.1)$ & \\
\hline \multicolumn{5}{|l|}{ Basal $(N=1683)$} \\
\hline Basal & $368(21.9)$ & $106(18.2)$ & $262(23.8)$ & 0.009 \\
\hline Non-Basal & $1315(78.1)$ & $475(81.8)$ & $840(76.2)$ & \\
\hline \multicolumn{5}{|l|}{ RandomGroup } \\
\hline E-CMF & $86(4.8)$ & $86(13.8)$ & $0(0.0)$ & $<0.001$ \\
\hline E-CMF-Doc & $182(10.4)$ & $0(0.0)$ & $182(15.8)$ & \\
\hline E-CMF-T & $199(11.2)$ & $0(0.0)$ & $199(17.4)$ & \\
\hline E-T-CMF & $1059(60.0)$ & $294(47.4)$ & $765(66.8)$ & \\
\hline ET-CMF & $240(13.6)$ & $240(38.8)$ & $0(0.0)$ & \\
\hline \multicolumn{5}{|l|}{ Survival data } \\
\hline Median FU in months & 72.5 & 118.4 & 65.6 & \\
\hline $\mathrm{N}$ of valid cases & 1764 & 620 & 1144 & $<0.001$ \\
\hline Deaths $(\mathrm{N})$ & 278 & 181 & 97 & \\
\hline Event-free at 3 years & 95.4 & 93.8 & 96.2 & \\
\hline Event-free at 5 years & 89.3 & 85.2 & 91.7 & \\
\hline Relapses (N) & 389 & 225 & 164 & $<0.001$ \\
\hline Event-free at 3 years & 88.0 & 82.8 & 90.9 & \\
\hline Event-free at 5 years & 82.2 & 74.5 & 86.5 & \\
\hline
\end{tabular}

All patients had informative NGS data.

Notes: MRM: modified radical mastectomy; FU: follow-up; N: number; IC-NST: invasive carcinoma of non-specific type; IHC: immunohistochemistry.

*Comparison of variable categories in the pre- and post- trastuzumab era series.

trend for longer DFS than those without $(\mathrm{HR}=0.69$ $95 \%$ CI $0.45-1.06 ; p=0.092$ ). Because trastuzumab was administered only in two of the analyzed studies (HE10/05 and HE10/08) we next assessed TP53 mutations separately in the pre- $[32,33]$ and posttrastuzumab [34] era. In the pre-trastuzumab era, TP53 mutations did not affect DFS (Figure 3C). Among patients who received trastuzumab, those with TP53 mutations fared marginally better as compared to those without (Figure 3D).

Domain specificity of mutations was associated with DFS in Luminal A/B and TNBC, while it was 
without effect in HER2-positive patients (Table 2). Analysis of the three most commonly mutated arginines (codons 175, 248 and 273) did not produce meaningful results due to the small sample size; it should be noticed however, that among the 19 patients with TP53 codon 248 mutations, only 1 patient with p.Arg248Gln relapsed after 80 months of treatment. The tumor was initially called TNBC, but was classified as Luminal B upon central testing. Immunopositivity for p53 significantly

A TP53, Luminal A/B

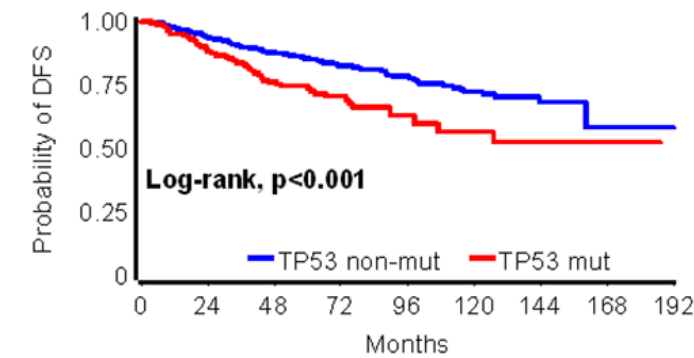

Patients at risk

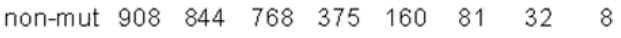

$\begin{array}{lllllllll}\text { mut } & 143 & 127 & 104 & 56 & 20 & 15 & 10 & 3\end{array}$

C TP53, HER2-positive, pre-trastuzumab

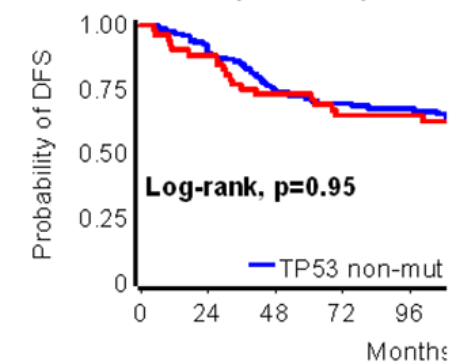

Patients at risk

non-mut $\begin{array}{lllll}149 & 133 & 109 & 99 & 81\end{array}$

$\begin{array}{llllll}\text { mut } & 52 & 46 & 38 & 32 & 28\end{array}$

E PIK3CA, HER2-positive, pre-trastuzumab

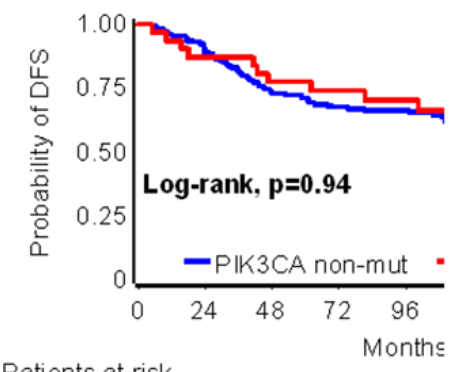

Patients at risk

non-mut $\begin{array}{lllll}170 & 152 & 123 & 109 & 92\end{array}$

$\begin{array}{llllll}\text { mut } & 31 & 27 & 24 & 22 & 17\end{array}$ affected DFS in patients with HER2-positive tumors only, in a way similar to that of TP53 mutations; HER2positive, p53 IHC positive tumors were associated with increased risk for relapse in the pre-trastuzumab era, while the same phenotype conferred favorable DFS in the post-trastuzumab era trials. No effect was observed for PIK3CA mutations when they were examined in the entire cohort including all subtypes. The presence of PIK3CA mutations resulted in favorable DFS for HER2-

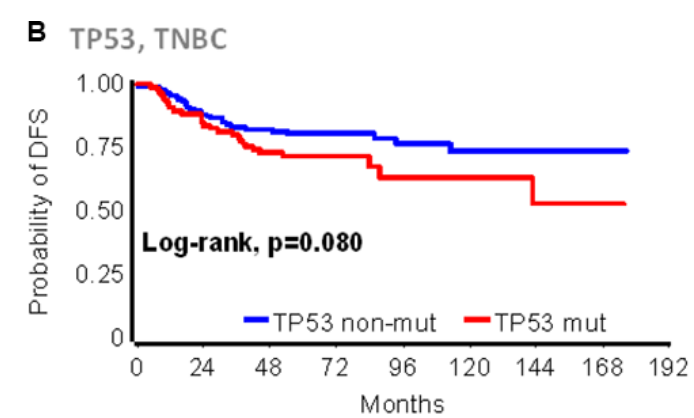

Patients at risk

$\begin{array}{lcccccccc}\text { non-mut } & 150 & 132 & 117 & 53 & 37 & 19 & 6 & 2 \\ \text { mut } & 85 & 72 & 61 & 24 & 15 & 10 & 4 & 1\end{array}$

D TP53, HER2-positive, post-trastuzumab

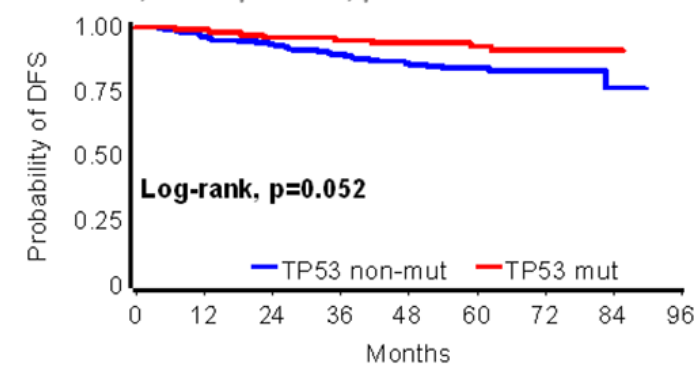

Patients at risk

$\begin{array}{lllllllll}\text { non-mut } & 179 & 171 & 165 & 158 & 148 & 104 & 43 & 7\end{array}$ $\begin{array}{llllllllll}\text { mut } & 98 & 97 & 94 & 93 & 89 & 65 & 22 & 1\end{array}$

F PIK3CA, HER2-positive, pre-trastuzumab

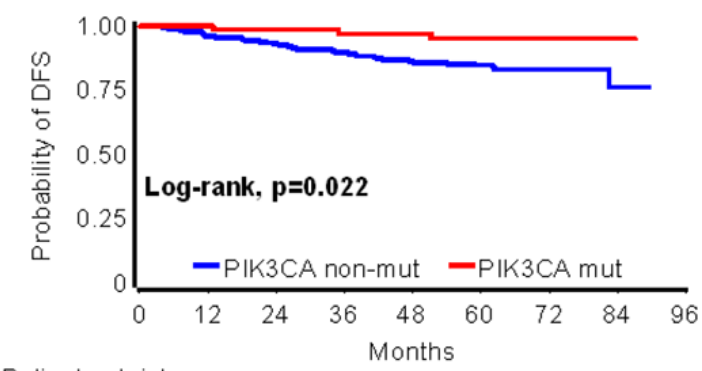

Patients at risk

non-mut $\begin{array}{lllllllll}214 & 205 & 197 & 190 & 177 & 129 & 49 & 6\end{array}$

$\begin{array}{lllllllll}\text { mut } & 63 & 63 & 62 & 61 & 60 & 40 & 16 & 2\end{array}$

Figure 3: TP53 and PIK3CA mutation effects on early breast cancer patient DFS according to main disease subtypes and trastuzumab treatment. The presence of TP53 mutations was unfavorable in Luminal A/B (A) and TNBC (B), indifferent in HER2-positive patients who were treated with anthracyclines only in the pre-trastuzumab era (C), but favorable in trastuzumab treated HER2-positive patients (D). (E) and (F): PIK3CA mutations in HER2-positive, non-trastuzumab and trastuzumab treated patients were similar to those described for TP53 mutations in (C) and (D), respectively. 
Table 2: Univariate cox regression analysis for TP53 and PIK3CA mutation (MUT) and for p53 protein expression by IHC against disease-free survival

\begin{tabular}{|c|c|c|c|c|c|}
\hline Parameter & $\mathrm{N}$ patients & $\mathrm{N}$ events & HR & $95 \% \mathrm{CI}$ & Wald's $p$ \\
\hline & \multicolumn{5}{|c|}{ ENTIRE COHORT } \\
\hline \multicolumn{6}{|l|}{ TP53 mutations } \\
\hline YES vs. NO & 380 vs. 1386 & 101 vs. 288 & 1.34 & $1.07-1.68$ & 0.011 \\
\hline TP53 mutation type & & & & & 0.014 \\
\hline missense vs. none & 267 vs. 1386 & 78 vs. 288 & 1.51 & $1.17-1.94$ & 0.001 \\
\hline fs-indels vs. none & 64 vs. 1386 & 13 vs. 288 & 0.99 & $0.57-1.73$ & 0.97 \\
\hline nonsense vs. none & 49 vs. 1386 & 10 vs. 288 & 0.96 & $0.51-1.8$ & 0.89 \\
\hline TP53 mutated domains & & & & & 0.03 \\
\hline DBD vs. none & 225 vs. 1386 & 63 vs. 288 & 1.42 & $1.08-1.86$ & 0.012 \\
\hline other vs. none & 155 vs. 1386 & 38 vs. 288 & 1.23 & $0.88-1.73$ & 0.23 \\
\hline \multicolumn{6}{|l|}{ PIK3CA mutations } \\
\hline YES vs. NO & 458 vs. 1308 & 89 vs. 300 & 0.83 & $0.65-1.05$ & 0.12 \\
\hline PIK3CA mutated domains & & & & & 0.12 \\
\hline kinase vs. none & 265 vs. 1308 & 57 vs. 300 & 0.94 & $0.71-1.24$ & 0.65 \\
\hline helical vs. none & 193 vs. 1308 & 32 vs. 300 & 0.68 & $0.48-0.99$ & 0.042 \\
\hline \multicolumn{6}{|l|}{ TP53 or PIK3CA mutations } \\
\hline YES vs. NO & 734 vs. 1032 & 159 vs. 230 & 0.97 & $0.79-1.19$ & 0.78 \\
\hline Mutation breakdown & & & & & 0.006 \\
\hline PIK3CA only vs. none & 354 vs. 1032 & 58 vs. 230 & 0.71 & $0.53-0.94$ & 0.018 \\
\hline TP53 only vs. none & 276 vs. 1032 & 70 vs. 230 & 1.17 & $0.90-1.53$ & 0.25 \\
\hline both vs. none & 104 vs. 1032 & 31 vs. 230 & 1.42 & $0.97-2.07$ & 0.068 \\
\hline \multicolumn{6}{|l|}{ p53 IHC $10 \%$ cut off } \\
\hline \multirow[t]{2}{*}{$\geq 10 \%$ vs. $<10 \%$} & 848 vs. 737 & 176 vs. 162 & 0.95 & $0.76-1.17$ & 0.61 \\
\hline & \multicolumn{5}{|c|}{ LUMINAL A/B } \\
\hline \multicolumn{6}{|l|}{ TP53 mutations } \\
\hline YES vs. NO & 143 vs. 908 & 47 vs. 171 & 1.86 & $1.34-2.57$ & $<0.001$ \\
\hline TP53 mutation type & & & & & $<0.001$ \\
\hline missense vs. none & 102 vs. 908 & 34 vs. 171 & 1.90 & $1.32-2.75$ & $<0.001$ \\
\hline fs-indels vs. none & 24 vs. 908 & 6 vs. 171 & 1.23 & $0.54-2.78$ & 0.62 \\
\hline nonsense vs. none & 17 vs. 908 & 7 vs. 171 & 2.71 & $1.27-5.78$ & 0.010 \\
\hline TP53 mutated domains & & & & & $<0.001$ \\
\hline DBD vs. none & 93 vs. 908 & 30 vs. 171 & 1.75 & $1.18-2.58$ & 0.005 \\
\hline other vs. none & 50 vs. 908 & 17 vs. 171 & 2.09 & $1.27-3.44$ & 0.004 \\
\hline \multicolumn{6}{|l|}{ PIK3CA mutations } \\
\hline YES vs. NO & 331 vs. 720 & 64 vs. 154 & 0.88 & $0.66-1.18$ & 0.39 \\
\hline PIK3CA mutated domains & & & & & 0.56 \\
\hline kinase vs. none & 185 vs. 720 & 38 vs. 154 & 0.95 & $0.66-1.35$ & 0.76 \\
\hline helical vs. none & 146 vs. 720 & 26 vs. 154 & 0.80 & $0.53-1.21$ & 0.29 \\
\hline
\end{tabular}




\begin{tabular}{|c|c|c|c|c|c|}
\hline TP53 or PIK3CA mutations & & & & & \\
\hline YES vs. NO & 423 vs. 628 & 92 vs. 126 & 1.07 & $0.82-1.41$ & 0.61 \\
\hline Mutation breakdown & & & & & $<0.001$ \\
\hline PIK3CA only vs. none & 280 vs. 628 & 45 vs. 126 & 0.78 & $0.55-1.08$ & 0.13 \\
\hline TP53 only vs. none & 92 vs. 628 & 28 vs. 126 & 1.58 & $1.05-2.38$ & 0.030 \\
\hline both vs. none & 51 vs. 628 & 19 vs. 126 & 1.99 & $1.23-3.23$ & 0.005 \\
\hline \multicolumn{6}{|l|}{ p53 IHC $10 \%$ cut off } \\
\hline \multirow[t]{2}{*}{$\geq 10 \%$ vs. $<10 \%$} & 485 vs. 456 & 96 vs. 94 & 0.93 & $0.7-1.24$ & 0.65 \\
\hline & \multicolumn{5}{|c|}{ TNBC } \\
\hline \multicolumn{6}{|l|}{ TP53 mutations } \\
\hline YES vs. NO & 85 vs. 150 & 27 vs. 32 & 1.58 & $0.94-2.63$ & 0.083 \\
\hline TP53 mutation type & & & & & 0.044 \\
\hline missense vs. none & 47 vs. 150 & 19 vs. 32 & 2.16 & $1.22-3.82$ & 0.008 \\
\hline fs-indels vs. none & 20 vs. 150 & 5 vs. 32 & 1.22 & $0.48-3.14$ & 0.68 \\
\hline nonsense vs. none & 18 vs. 150 & 3 vs. 32 & 0.71 & $0.22-2.32$ & 0.57 \\
\hline TP53 mutated domains & & & & & 0.14 \\
\hline DBD vs. none & 41 vs. 150 & 15 vs. 32 & 1.86 & $1.01-3.45$ & 0.047 \\
\hline other vs. none & 44 vs. 150 & 12 vs. 32 & 1.32 & $0.68-2.57$ & 0.41 \\
\hline \multicolumn{6}{|l|}{ PIK3CA mutations } \\
\hline YES vs. NO & 33 vs. 202 & 10 vs. 49 & 1.27 & $0.64-2.51$ & 0.50 \\
\hline PIK3CA mutated domains & & & & & 0.068 \\
\hline kinase vs. none & 21 vs. 202 & 9 vs. 49 & 2.00 & $0.98-4.08$ & 0.056 \\
\hline helical vs. none & 12 vs. 202 & 1 vs. 49 & 0.29 & $0.04-2.13$ & 0.22 \\
\hline \multicolumn{6}{|l|}{ TP53 or PIK3CA mutations } \\
\hline YES vs. NO & 103 vs. 132 & 31 vs. 28 & 1.47 & $0.88-2.46$ & 0.14 \\
\hline Mutation breakdown & & & & & 0.29 \\
\hline PIK3CA only vs. none & 18 vs. 132 & 4 vs. 28 & 1.01 & $0.36-2.89$ & 0.98 \\
\hline TP53 only vs. none & 70 vs. 132 & 21 vs. 28 & 1.47 & $0.84-2.6$ & 0.18 \\
\hline both vs. none & 15 vs. 132 & 6 vs. 28 & 2.10 & $0.87-5.09$ & 0.10 \\
\hline \multicolumn{6}{|l|}{ p53 IHC $10 \%$ cut off } \\
\hline \multirow[t]{2}{*}{$\geq 10 \%$ vs. $<10 \%$} & 113 vs. 102 & 30 vs. 25 & 1.09 & $0.64-1.86$ & 0.74 \\
\hline & \multicolumn{5}{|c|}{ HER2-positive, pre-trastuzumab } \\
\hline \multicolumn{6}{|l|}{ TP53 mutations } \\
\hline YES vs. NO & 52 vs. 149 & 19 vs. 55 & 1.01 & $0.6-1.7$ & 0.97 \\
\hline TP53 mutation type & & & & & 0.48 \\
\hline missense vs. none & 42 vs. 149 & 18 vs. 55 & 1.28 & $0.75-2.19$ & 0.36 \\
\hline fs-indels vs. none & 6 vs. 149 & 1 vs. 55 & 0.62 & $0.12-3.22$ & 0.57 \\
\hline nonsense vs. none & 4 vs. 149 & 0 vs. 55 & 0.20 & $0.01-3.72$ & 0.28 \\
\hline TP53 mutated domains & & & & & 0.46 \\
\hline DBD vs. none & 31 vs. 149 & 13 vs. 55 & 1.27 & $0.7-2.33$ & 0.43 \\
\hline other vs. none & 21 vs. 149 & 6 vs. 55 & 0.69 & $0.29-1.62$ & 0.38 \\
\hline
\end{tabular}




\begin{tabular}{|c|c|c|c|c|c|}
\hline \multicolumn{6}{|l|}{ PIK3CA mutations } \\
\hline YES vs. NO & 31 vs. 170 & 12 vs. 62 & 1.03 & $0.55-1.9$ & 0.94 \\
\hline PIK3CA mutated domains & & & & & 0.96 \\
\hline kinase vs. none & 17 vs. 170 & 7 vs. 62 & 1.10 & $0.5-2.41$ & 0.81 \\
\hline helical vs. none & 14 vs. 170 & 5 vs. 62 & 0.93 & $0.38-2.33$ & 0.89 \\
\hline \multicolumn{6}{|l|}{ TP53 or PIK3CA mutations } \\
\hline YES vs. NO & 72 vs. 129 & 27 vs. 47 & 1.01 & $0.63-1.62$ & 0.97 \\
\hline Mutation breakdown & & & & & $<0.99$ \\
\hline PIK3CA only vs. none & 20 vs. 129 & 8 vs. 47 & 1.01 & $0.48-2.13$ & 0.99 \\
\hline TP53 only vs. none & 41 vs. 129 & 15 vs. 47 & 1.00 & $0.55-1.79$ & 0.99 \\
\hline both vs. none & 11 vs. 129 & 4 vs. 47 & 1.07 & $0.38-2.95$ & 0.91 \\
\hline \multicolumn{6}{|l|}{ p53 IHC $10 \%$ cut off } \\
\hline \multirow[t]{2}{*}{$\geq 10 \%$ vs. $<10 \%$} & 92 vs. 86 & 38 vs. 23 & 1.71 & $1.02-2.87$ & 0.043 \\
\hline & \multicolumn{5}{|c|}{ HER2-positive, post-trastuzumab } \\
\hline \multicolumn{6}{|l|}{ TP53 mutations } \\
\hline YES vs. NO & 98 vs. 179 & 8 vs. 30 & 0.47 & $0.22-1.02$ & 0.06 \\
\hline TP53 mutation type & & & & & 0.45 \\
\hline missense vs. none & 76 vs. 179 & 7 vs. 30 & 0.56 & $0.25-1.27$ & 0.16 \\
\hline fs-indels vs. none & 13 vs. 179 & 1 vs. 30 & 0.72 & $0.13-3.87$ & 0.70 \\
\hline nonsense vs. none & 10 vs. 179 & 0 vs. 30 & 0.28 & $0.02-4.89$ & 0.38 \\
\hline TP53 mutated domains & & & & & 0.16 \\
\hline DBD vs. none & 60 vs. 179 & 5 vs. 30 & 0.47 & $0.18-1.23$ & 0.12 \\
\hline other vs. none & 38 vs. 179 & 3 vs. 30 & 0.46 & $0.14-1.5$ & 0.20 \\
\hline \multicolumn{6}{|l|}{ PIK3CA mutations } \\
\hline YES vs. NO & 63 vs. 214 & 3 vs. 35 & 0.28 & $0.09-0.9$ & 0.032 \\
\hline PIK3CA mutated domains & & & & & 0.18 \\
\hline kinase vs. none & 42 vs. 214 & 3 vs. 35 & 0.47 & $0.15-1.45$ & 0.19 \\
\hline helical vs. none & 21 vs. 214 & 0 vs. 35 & 0.14 & $0.01-2.37$ & 0.17 \\
\hline \multicolumn{6}{|l|}{ TP53 or PIK3CA mutations } \\
\hline YES vs. NO & 134 vs. 143 & 9 vs. 29 & 0.31 & $0.15-0.66$ & 0.002 \\
\hline Mutation breakdown & & & & & 0.026 \\
\hline PIK3CA only vs. none & 36 vs. 143 & 1 vs. 29 & 0.13 & $0.02-0.92$ & 0.042 \\
\hline TP53 only vs. none & 71 vs. 143 & 6 vs. 29 & 0.39 & $0.16-0.95$ & 0.038 \\
\hline both vs. none & 27 vs. 143 & 2 vs. 29 & 0.34 & $0.08-1.44$ & 0.14 \\
\hline \multicolumn{6}{|l|}{ p53 IHC $10 \%$ cut off } \\
\hline$\geq 10 \%$ vs. $<10 \%$ & 160 vs. 92 & 12 vs. 20 & 0.31 & $0.15-0.64$ & 0.002 \\
\hline
\end{tabular}

Notes: TAD: transactivation domain; DBD: DNA binding domain; TETRA: oligomerization domain; IHC: Immunohistochemistry; Luminal A/B: ER/PgR positive, HER2 negative.

positive patients in the post-, but was without effect in the pre-trastuzumab era trials (Figure $3 \mathrm{E}$ and $3 \mathrm{~F}$ ); PIK3CA mutations and their domain specificity were without effect in the Luminal A/B and TNBC groups. TP53 and PIK3CA co-mutated tumors conferred increased risk for relapse in Luminal A/B patients only, but not in the other subtypes. Finally, among HER2positive, trastuzumab-treated patients, the presence of either TP53 or PIK3CA mutations was associated with favorable DFS; by contrast, the presence of either 
mutant gene predicted for worse DFS in HER2-positive patients in the post-trastuzumab era trials (Table 2).

\section{TP53 mutations and p53 protein status interacted with trastuzumab benefit}

The HER2-subtype-specific diverse effects of TP53 and PIK3CA mutations, as well as those of $\mathrm{p} 53$ protein expression, prompted us to further investigate a possible role of these characteristics in predicting trastuzumab benefit. For this purpose, the pre-trastuzumab studies were excluded from the analyses, due to the respective much longer followup as compared to the post-trastuzumab studies (Table 1). Trastuzumab had been administered according to local HER2-positive diagnosis over a period of 7 years. Upon retrospective testing, 50 tumors were centrally characterized as HER2-positive although they were HER2-negative when locally assessed and those patients had therefore not received trastuzumab. For testing putative interactions between mutations or p53 protein expression and trastuzumab, we compared this 50-patient, HER2-positive non-treated group against 177 patients with locally and centrally HER2-positive tumors that had been treated with the drug. In contrast to the pre- and post-trastuzumab HER-positive groups that did not differ with respect to ER/PgR status, the non-treated 50-patient subset was richer in $\mathrm{ER} / \mathrm{PgR}$ positive tumors than the HER2-concordant subset (Supplementary File S1, Part A).

By comparing DFS in the above patient subsets, TP53 mutations interacted with trastuzumab (interaction $p=0.017$ ) and in a similar way with $\mathrm{p} 53$ immnopositivity (interaction $p=0.015$ ) (Table 3 ). In particular, among patients with TP53 mutations (Figure $4 \mathrm{~A}$ ) or p53 immunopositivity (Figure 4B), those treated with trastuzumab had longer DFS than those not treated; in addition, the same TP53 markers conferred longer DFS in patients treated with trastuzumab but not in those who were not treated with the drug.

In contrast to TP53 mutations and protein expression, no interaction was identified for PIK3CA mutations with trastuzumab when comparing the same patient groups (Table 3).

\section{TP53 mutations and p53 protein status as subtype-specific independent prognosticators}

Based on the subtype-specific impact of TP53 and PIK3CA mutations, and of p53 protein expression, multivariate analyses were performed in the three major subsets of breast cancer patients, i.e., Luminal A/B, TNBC and HER2-positive, the latter in the pre- and posttrastuzumab era. The impact of TP53 mutations, PIK3CA mutations, p53 protein expression and their interactions with trastuzumab on patient DFS was adjusted for standard clinicopathological parameters (Table S5) in three different settings, (i) in the entire patient population by local pathology subtyping, upon which the administration of hormone therapy and trastuzumab was based (Figure 5); (ii) in centrally typed HER2-positive cases, for which the interactions with trastuzumab were identified, as described above (Table S6); and, (iii) in cases with concordant subtyping upon local and central testing (Table S7). The latter approach was undertaken as a more stringent validation of the above findings concerning TP53 mutations and p53 protein expression. Discordance rates according to ER/PgR and HER2 positivity are shown in Table S8.

TP53 mutations and their domain specificity were significantly unfavorable in Luminal $\mathrm{A} / \mathrm{B}$ and $\mathrm{TNBC}$ in the entire cohort (Figure 5, Table S9) and retained their significance in Luminal A/B concordant patients (Table S7 and Table S10). For HER2-positive patients in the post-trastuzumab era, the interaction between TP53 mutations or p53 protein expression and trastuzumab was independently significant for DFS, whereby positivity for these markers conferred decreased risk for relapse in trastuzumab-treated patients. In the pretrastuzumab era trials, TP53 mutations were either not retained in the model or, if significant, they were associated with a higher risk for relapse, the opposite effect than the one observed in the post-trastuzumab era trials.

\section{DISCUSSION}

The primary objective of the present study was to investigate important associations of tumor TP53 and PIK3CA mutations with clinical outcome in patients with early breast cancer enrolled in four prospective clinical studies. Following targeted next generation sequencing genotyping in 1766 FFPE DNA samples, PIK3CA and TP53 gene mutations were found in $25.9 \%$ and $21.5 \%$ of the patients, respectively, percentages that are remarkably similar to those reported for breast cancer in the Catalog of Somatic Mutations in Cancer (COSMIC, 26\% and $23 \%$, respectively) [35]. Additionally, in line with the published literature $[17,36]$, the majority of mutations in both genes were missense. Most of the TP53 mutations were found in the DNA binding domain, as has also been reported by others [16], while PIK3CA mutations in the helical and kinase domains were found at the expected incidence for the three hot-spot codons, as has been repetitively reported [37].

As previously stated, TP53 mutations have been linked to reduced survival of patients with breast cancer compared to wild-type TP53. As we are deepening our knowledge in tumor cell biology, it is becoming increasingly evident that the properties of specific mutants with regard to tumor progression and their 
Table 3: Interaction testing between study variables and trastuzumab (T) treatment in HER2positive patients

\begin{tabular}{|c|c|c|c|c|c|}
\hline Parameter & $N$ patients & $N$ events & HR & $95 \% \mathrm{CI}$ & Wald's $p^{\wedge}$ \\
\hline TP53 mutations (MUT) & & & & & 0,017 \\
\hline TP53 MUT, YES vs. NO@ T-treated* & 75 vs. 102 & 4 vs. 15 & 0.35 & $0.12-1.06$ & \\
\hline TP53 MUT, YES vs. NO@ non-T-treated** & 13 vs. 36 & 5 vs. 7 & 2.43 & $0.77-7.68$ & \\
\hline T-treated vs. non-T-treated @ TP53 MUT, NO & 102 vs. 36 & 15 vs. 7 & 0.69 & $0.28-1.68$ & \\
\hline T-treated vs. non-T-treated @, TP53 MUT, YES & 75 vs. 13 & 4 vs. 5 & 0.10 & $0.03-0.37$ & \\
\hline p53 IHC (10\% cut-off) & & & & & 0,015 \\
\hline p53 IHC, $\geq 10 \%$ vs. $<10 \% @$ T-treated & 114 vs. 52 & 5 vs. 13 & 0.15 & $0.05-0.42$ & \\
\hline p53 IHC, $\geq 10 \%$ vs. $<10 \% @$ non-T-treated & 25 vs. 20 & 6 vs. 5 & 1.05 & $0.32-3.46$ & \\
\hline T-treated vs. non-T-treated @ p53 IHC, <10\% & 52 vs. 20 & 13 vs. 5 & 1.01 & $0.36-2.82$ & \\
\hline T-treated vs. non-T-treated @ p53 IHC, $\geq 10 \%$ & 114 vs. 25 & 5 vs. 6 & 0.14 & $0.04-0.47$ & \\
\hline PIK3CA mutations (MUT) & & & & & 0,25 \\
\hline PIK3CA MUT, YES vs. NO@ T-treated & 37 vs. 140 & 2 vs. 17 & 0.43 & $0.1-1.87$ & \\
\hline PIK3CA MUT, YES vs. NO@ non-T-treated & 13 vs. 37 & 4 vs. 8 & 1.31 & $0.39-4.36$ & \\
\hline T-treated vs. non-T-treated @ PIK3CA MUT, NO & 140 vs. 37 & 17 vs. 8 & 0.46 & $0.2-1.07$ & \\
\hline T-treated vs. non-T-treated@ @IK3CA MUT, YES & 37 vs. 13 & 2 vs. 4 & 0.15 & $0.03-0.83$ & \\
\hline
\end{tabular}

Notes: T: trastuzumab; IHC: Immunohistochemistry; ${ }^{\wedge}$ : interaction p; *: HER2 status positive upon local and central testing, treated with trastuzumab; **: HER2 status negative upon local, positive upon central testing, not treated with trastuzumab.

clinical applications remain unclear $[35,38]$. In the present study no specific effect for missense, nonsense or frameshift TP53 mutations was revealed. In line with earlier evidence [39], we have also demonstrated the unfavorable effect of DNA binding domain mutations. As suggested [40], however, not all of these mutations have the same impact on patient outcome. For example, as shown here, p.Arg248Gln mutations may confer favorable prognosis. This is in contrast to the unfavorable prognostic effect previously assigned to the same mutation [13], the reason probably being that patient subsets with specific mutated codons are small within individual studies. Nevertheless, since the present study included Greek patients only, this type of information is noteworthy because notable differences in the spectrum or prognostic impact of mutations, especially in TP53, have been reported among different ethnic groups or geographical regions, possibly due to the link with environmental mutagens [41, 42]. Such differences may be crucial when evaluating results of multinational clinical trials, investigating novel targeted agents.

With respect to disease characteristics, this study confirms the prevalence of TP53 mutations in ER/ PgR-negative and that of PIK3CA mutations in ER/ PgR-positive tumors [10]. In accordance with PIK3CA mutations developing in a hormone receptor rich environment, these mutations were more frequently observed in lobular than in ductal carcinomas, a finding that has been reported by others, as well [36]. However, contrary to the published literature $[13,43]$ and the predominant view that the presence of TP53 mutations are more frequent in high-grade, large-size, nodepositive breast cancers, we did not observe, with the exception of histological grade, a significant association between TP53 mutations and menopausal status, tumor size or nodal status. This discrepancy may well be due to a selection bias in patient populations of prospective clinical trials (as in the case of the present study), in which only patients with intermediate or high-risk cancers were included, as opposed to unselected series [43].

The above subtype specificity of TP53 and PIK3CA mutations is reflected in the impact of these mutations on patient DFS. In a thorough study of the spectrum of TP53 mutations, Silwal-Pandit et al. [15] obtained 1420 tumor samples from the METABRIC cohort [43] and sequenced all coding exons of the TP53 gene. By using the PAM50 classifier, they concluded that TP53 mutations were associated with worse prognosis in patients with Luminal B, HER2-enriched and normallike tumors, but not in patients with Luminal A or Basal-like tumors. In a partial overlap with this report, herein we show that for tumors subtyped with IHC and HER2 FISH, where needed, TP53 mutations were strong independent adverse prognosticators in patients with Luminal A/B and TNBC, but not in patients with HER2-positive tumors. The observed differences most probably reflect the approximately $40 \%$ discrepancy rate between the two subtyping approaches [31, 44]. In 
the case of Luminal A/B tumors, where TP53 mutations were strongly unfavorable, our data seem to support that TP53 mutation dependence, once established, provides a more severe pro-oncogenic activity compared to the co-existing hormone dependence $[13,35]$. As shown, TP53 mutations were unfavorable in ER/PgR-positive HER2-negative tumors irrespectively of Luminal A and Luminal B distinction. Although the rate of TP53 mutations in Luminal A/B tumors was the lowest among the major breast cancer subtypes, the number of patients with such mutations is considerably large. In the context of the world-wide applied clinical subtyping, the adverse prognostic effect of TP53 mutations in this large group of patients is a novel finding that merits further clinical investigation.

In contrast to TP53 mutations, no prognostic role was revealed here for $\mathrm{p} 53$ protein expression in the entire cohort or in Luminal $\mathrm{A} / \mathrm{B}$ and TNBC patients,

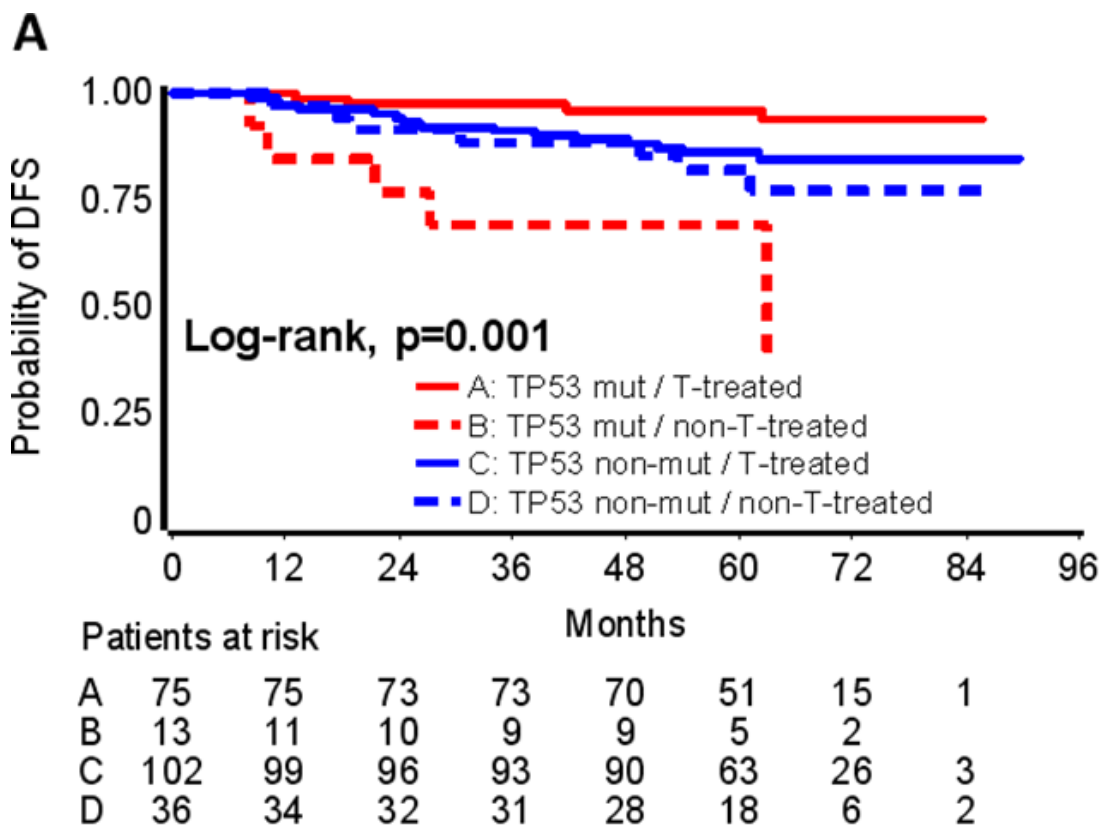

B

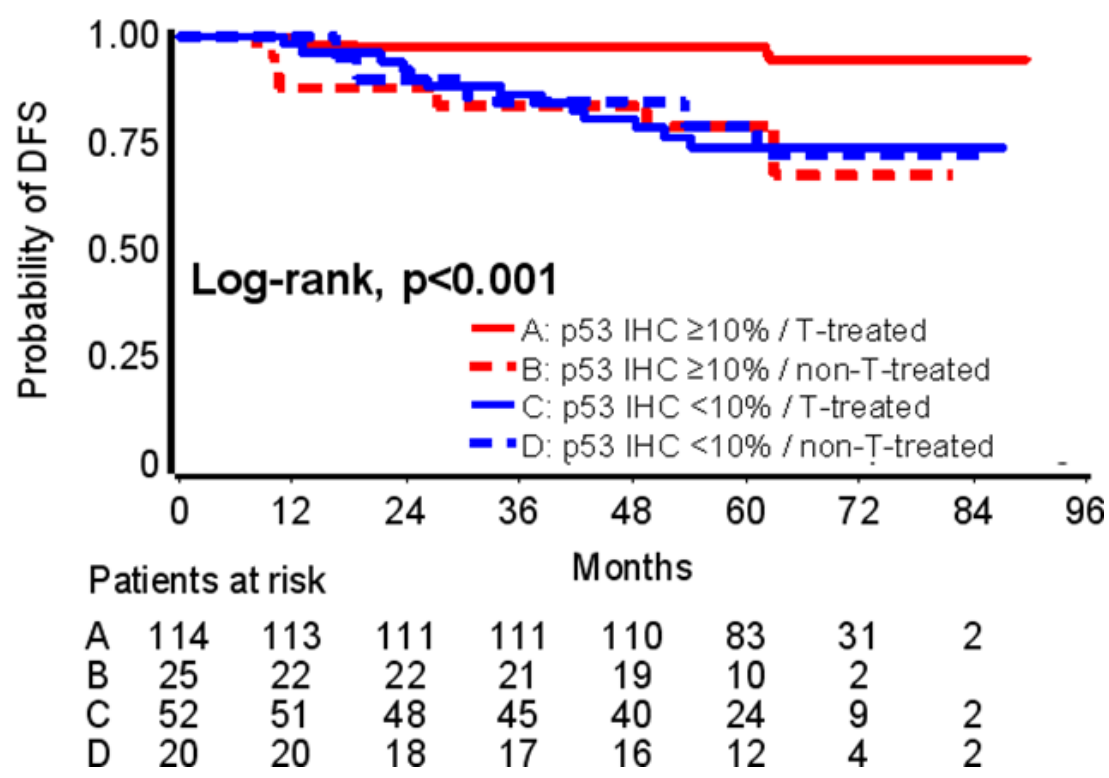

Figure 4: TP53 mutations predictive for trastuzumab benefit. Interactions between TP53 mutations and trastuzumab (A), and between p53 protein expression and trastuzumab (B) are shown. Trastuzumab (T) treated patients with TP53 mutations (A) or p53 positive protein expression by IHC (B) fared best; patients with the same TP53 tumor properties, who were not treated with trastuzumab, fared worst. 
in line with the CALGB 9344 study [25] that used the anti-p53 DO7 clone, as well. These findings cannot however be compared to the other two existing studies reporting on the poor prognosis of p53 immunopositive luminal tumors [23, 24], because of different IHC scoring systems and antibodies used.

TP53 mutations have been associated with response to various treatments of breast cancer [12]. Patients in the present study had been treated with adjuvant regimens comprised of an anthracycline, taxanes and CMF. Contradictory results regarding TP53 mutations and response to anthracycline-based chemotherapy, mainly in the neo-adjuvant setting, have been published, with some studies indicating chemosensitivity with improved pathological complete response rates $[45,46]$, while others are suggestive of chemoresistance [47-49]. Associations of TP53 mutations with response to anti-HER2 treatments have been reported mainly in the neo-adjuvant setting [5052]. The present study is perhaps the first to indirectly show a favorable predictive effect of TP53 mutations and, intriguingly, p53 immnopositivity for trastuzumab benefit in the adjuvant setting. Herein, we compared the outcome of HER2-positive patients that were either treated or not with trastuzumab, although the latter did not a priori comprized a specific control group. Based on the present findings, p53 dysfunction may favor trastuzumab-specific responses in the adjuvant setting.
Clearly, these findings are hypothesis generating. If further validated, the potential predictive role of p53pathway aberrations for trastuzumab benefit may have important implications in the assessment of patients with HER2-positive operable disease.

PIK3CA mutational status has also been proposed as a potential marker of trastuzumab response. Preclinical studies indicate that PIK3CA mutations activate signaling downstream of HER2, resulting in relative resistance to HER2-targeted agents, including trastuzumab and lapatinib [37, 53-55]. Regarding the role of PIK3CA mutations in patients with HER2positive operable or metastatic disease treated with anti-HER2 agents, at present, existing data are inconclusive. In the FinHER trial [56], patients with PIK3CA mutations had a better prognosis only during the first three years from randomization, but such mutations were not predictive for trastuzumab benefit [36]. Similarly, in the NSABP B31 trial [57], PIK3CA mutations were not predictive for trastuzumab benefit in the HER2-Enriched subtype, as defined by the PAM50 classifier [58]. On the other hand, genomic data from neo-adjuvant trials with anti-HER2 agents, strongly indicate that the presence of PIK3CA mutations predicted for poor pathological complete response and compromized survival [59-63]. In our series, PIK3CA mutations were not prognostic in Luminal $\mathrm{A} / \mathrm{B}$ and TNBC patients, did not interact with trastuzumab

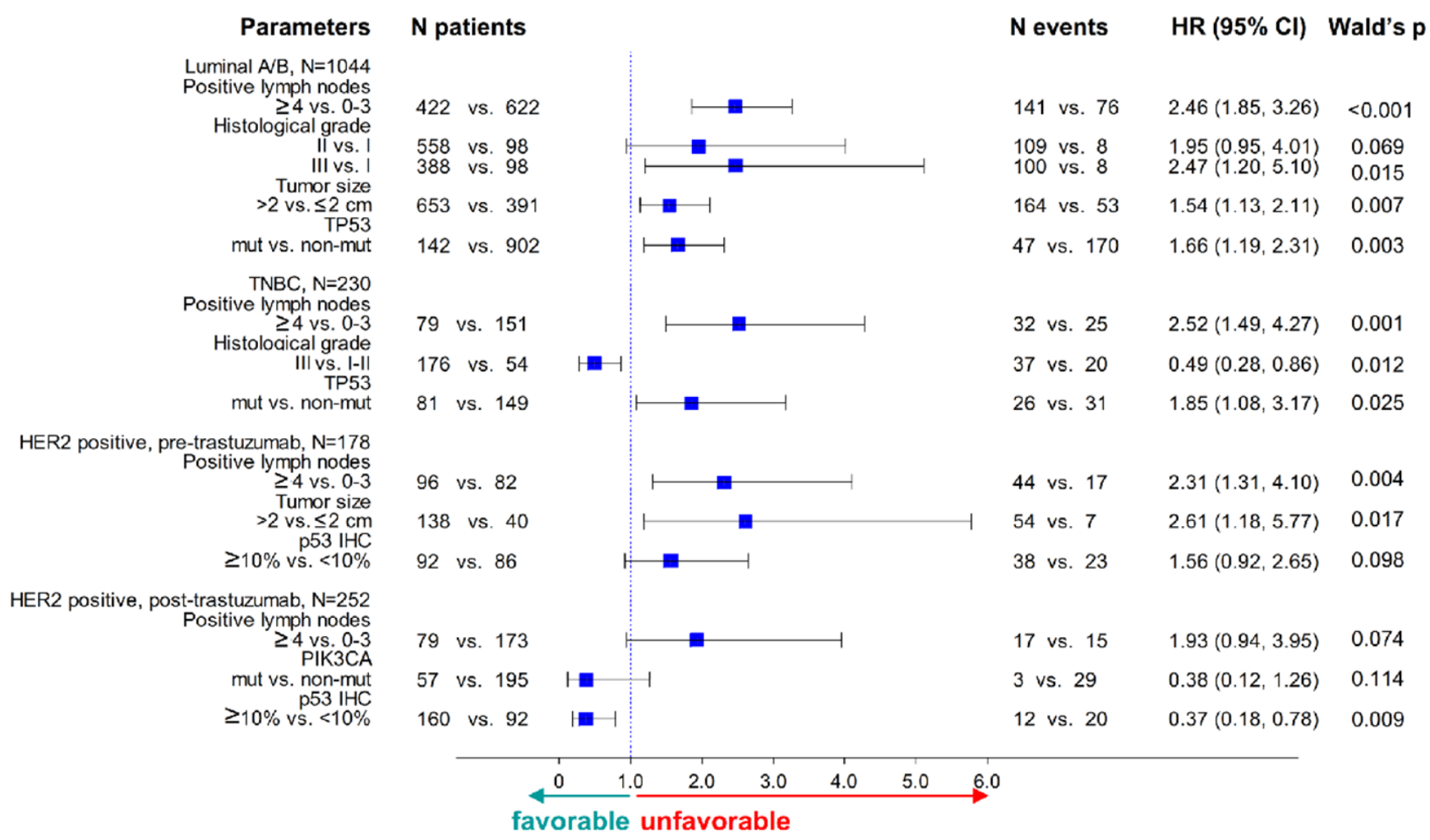

Figure 5: Forest plots for multivariable analyses in the entire cohort. TP53 mutations and p53 protein expression were included in all models. p53 IHC positivity was unfavorable in HER2-positive patients not treated but favorable in those treated with trastuzumab. 
treatment, while they lost their prognostic significance in trastuzumab-treated patients upon multivariate analysis. These data are in line with the adjuvant studies cited above. Possible points to be addressed in future studies in the adjuvant setting with respect to evaluating the importance of PIK3CA mutations, are larger numbers of PIK3CA only mutant tumors, which, as shown here, behave differently than those co-mutated with TP53; perhaps studying mutations with proven oncogenic potential among all mutations identified with next generation sequencing platforms; and, ensuring statistical power for PIK3CA mutant patient subsets, such as those with HER2-positive tumors.

In conclusion, in the present series, a definite prognostic/predictive role of PIK3CA mutations could not be demonstrated. On the other hand, TP53 mutations may be helpful in predicting poor prognosis in early breast cancer patients with Luminal A/B tumors and probably with TNBC, while immunopositivity for $\mathrm{p} 53$ protein may be predictive for adjuvant trastuzumab benefit. These findings, especially the potential value of positive p53 protein status, by the widely used IHC method, as a predictive marker for trastuzumab benefit, are worth validating in independent large prospective studies.

\section{MATERIALS AND METHODS}

Tumor tissue material was examined from 2252 patients out of 3451 who had been diagnosed between 1997 and 2010 with operable breast cancer and had been treated with adjuvant chemotherapy (anthracyclines - taxanes) in the setting of four prospective clinical trials by the Hellenic Cooperative Oncology Group (HeCOG) (Figure 6). The basic trial characteristics are shown in Table S11. In HE10/97 [32] and HE10/00 [33] trastuzumab was not administered (pre-trastuzumab era). In HE10/05 [34] and HE10/08 (manuscript in preparation) trastuzumab was administered sequentially for one year after the completion of chemotherapy

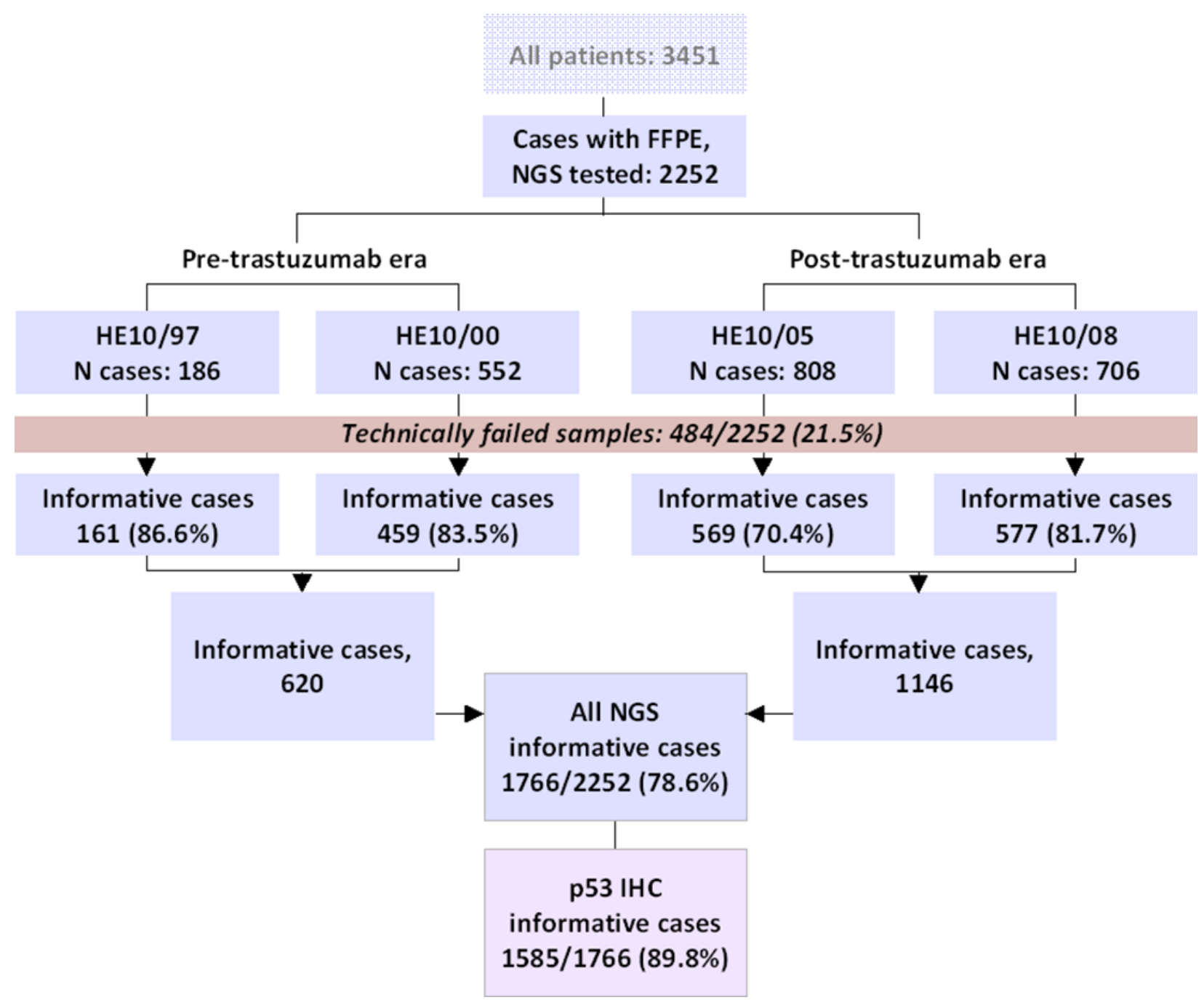

Figure 6: REMARK chart. All samples examined in this study have yielded informative NGS results. Immunohistochemistry (IHC) for p53 protein expression was applied on available tissues in the majority of the NGS informative samples. 
(post-trastuzumab era). Patients had provided written consent for the use of their biologic material for research purposes and the study was approved by the Bioethics Committee of the Aristotle University of Thessaloniki School of Health Sciences, Faculty of Medicine (\#77/10June2014) and by the Institutional Review Board of the Papageorgiou Hospital of Thessaloniki (\#725/10May2013). Paraffin blocks were collected retrospectively for HE10/97 and prospectively for the other three trials. The distribution of patients and tumors per clinical study and basic demographic, clinicopathological, follow-up and outcome data are shown in Table 1.

Tumors had been routinely diagnosed in local pathology laboratories, where they had also been evaluated for $\mathrm{ER} / \mathrm{PgR} / \mathrm{HER} 2$ protein expression with immunohistochemistry (IHC) and, in HE10/05 and in HE10/08, with FISH or CISH for HER2 IHC $2+$ cases. Patients were stratified according to local testing for receiving hormone treatment (all trials) and trastuzumab (HE10/05 and HE10/08). For the purpose of the present study, based on local testing results, tumors were classified as Luminal A/B for combined $\mathrm{ER} / \mathrm{PgR}$ positivity in the absence of HER2 protein overexpression and/or gene amplification; as triple negative (TNBC) if ER/PgR/HER2 negative; and, as HER2-positive, if HER2 IHC 3+ and/or HER2 FISH positive, independently of ER/PgR status.

The available paraffin blocks (routinely processed formalin-fixed paraffin-embedded, FFPE) were also centrally processed at the Laboratory of Molecular Oncology (Hellenic Foundation for Cancer Research/ Aristotle University of Thessaloniki, Thessaloniki, Greece). Processing involved thorough central histological review by three experienced pathologists (S.L., M.B., A.B.), parameter recording and marking tumor-dense areas for macro-dissection and tissue microarray (TMA) construction. Low-density TMA blocks carried $2 \times 1.5 \mathrm{~mm}$ cores from different areas of each tumor. All tumors were clinically subtyped with ER/ $\mathrm{PgR} / \mathrm{HER} 2 / \mathrm{Ki} 67 \mathrm{IHC}$ and FISH, as previously described [64] with the Ki67 cut-off at 14\% for distinguishing between Luminal A and Luminal B tumors. In addition, cytokeratin-5 (CK5) and epidermal growth factor receptor (EGFR) IHC was applied for typing basal-like carcinomas, with $1 \%$ cut-off for positivity, as suggested [65].

\section{DNA extraction and tissue processing for next generation sequencing (NGS)}

Paraffin tumor sections were processed for DNA extraction upon manual macro-dissection in order to enrich samples for tumor DNA, as previously described [66] or, in the case of HE10/97, from TMA cores, $1.5 \mathrm{~mm}$ in diameter $(5 \times 8 \mathrm{um}$ sections, 2 cores per tumor). Tumor cell content (TCC) was assessed as an approximate metric for tumor DNA in the extracted samples, corresponding to tumor nuclei vs. all nuclei in the areas marked for macro-dissection and on the TMA cores. The majority of samples (52\%) had TCC $\geq 50 \%$ but samples with as low as $15 \%$ TCC were also processed, since it proved possible to orthogonally validate variants in such samples [67]. DNA was extracted with magnetic beads (VERSANT Tissue Prep Kit, Siemens Healthcare, Erlangen, Germany). DNA quantity was measured with the Qubit fluorometer (Life Technologies, Paisley, UK) and amplification performance of the template was evaluated by qPCR. Criteria for processing samples for NGS were $\geq 2 \mathrm{ng}$ / ul DNA amplifiable at $\mathrm{Ct} \leq 32$ for two different qPCR control assays; based on these criteria, 135 out of 2252 samples $(6 \%)$ were not processed for NGS due to inadequate DNA.

\section{NGS and variant analysis}

Samples were sequenced in an Ion Proton Sequencer with standard procedures for library and sequencing preparation for a highly-multiplexed previously validated panel [67]. As described, the B-panel that was used in the present series covered $\sim 35$ $\mathrm{Kb}$ with 373 amplicons in 60 genes, including the entire coding region of TP53, and exons 2, 10, 11, 20 and 21 of PIK3CA. Up to 48 samples were sequenced per PI chip. For data retrieval, base calling was performed on the Torrent Server using Torrent Suite v.3.6.2 and v.4.0. Following base calling and the generation of sequence reads, the pipeline by Torrent Suite included adapter sequence trimming, read alignment to the human reference genome (hg19) and variant calling. Variant annotation was performed by Ion Reporter v.4.0. Raw annotated data from Ion Reporter v.4.0 were evaluated for the reads of all amplicons in the panel and further quality filtered for accepting eligible variants, in the following order: eligible amplicons should have > 100 reads; the variant calling $p$-value threshold was strengthened to 0.0001 instead of the default 0.05 ; variant position coverage was accepted if $>100$; and, variants were accepted for alternative allele coverage $>$ 40; non-annotated variants, as well as indels involving G-stretches (possibly artifacts with semiconductor sequencing) were excluded. Variant allele frequencies of $>5 \%$ were accepted by default. The $>100$ threshold for amplicon and position coverage was assessed in sample replicates for single nucleotide variants; with this threshold, the Pearson correlation coefficient of variant allele frequencies across replicates was 0.99 (Supplementary File S1, Part B and Figure S1).

For the purposes of the present work, exonic variants in the TP53 and PIK3CA genes were analyzed as mutations if these were non-synonymous and in the case of annotated single nucleotide polymorphisms (SNPs) they had registered minor allele frequency 
$(\mathrm{MAF})<0.1 \%$, thus excluding even very rare variants in the population [68]. Although methods for bioinformatically predicting the pathogenicity of variants have been succesfully employed in the analysis of germline DNA [69], predicting the functional consequences of cancer mutations has been difficult [70]. Hence we did not attempt to discriminate between driver and passenger mutations using automated methods.

Samples were excluded from the analysis if they had $<10$ variants in any of the genes tested and/or if $>90 \%$ of the amplicons were covered $<100$ times. With this criterion, another 349 samples (15.5\%) were considered as technically failed; finally, primary tumors from 1766 patients were eligible for statistical analysis (Figure 6). TP53 and PIK3CA NGS variants were orthogonally validated with dd-sequencing, as previously shown for this panel $[67,71]$.

\section{IHC for $\mathbf{p 5 3}$ protein status}

IHC was performed on 2 um thick TMA sections with the p53 monoclonal antibody (clone DO7; DAKO, Glostrup, DK) at a concentration 1:100 in a Bond MaxTM autostainer (Leica Microsystems, Wetzlar, Germany), upon antigen retrieval in citric acid for 20 min. Tumors with $\geq 10 \%$ nuclear staining of any intensity were considered immunopositive for p53 protein $[25,72]$.

\section{Statistical analysis}

The analysis was conducted in the entire cohort and by local pathology subtyping, separately for pre(HE10/97 \& HE10/00) and post-trastuzumab era studies (HE10/05 \& HE10/08).

Continuous variables were presented by the use of various measures (mean, standard deviation, median, range), while categorical variables as frequencies and corresponding percentages. TP53 and PIK3CA mutations were analyzed for the presence or absence as binary variables; as a 4-scale variable for co-mutated tumors; as missense and nonsense/ frameshifts; and for domain specificity, according to the most commonly affected coding area for each gene. Associations among demographic, clinical, tumor and treatment characteristics, as well as among p53 protein expression, TP53 and PIK3CA mutations and domains, were examined. For categorical variables the chi-square or Fisher's exact tests were used, where appropriate, while for testing categorical with continuous variables the Mann-Whitney or the Kruskal-Wallis tests were used. Concordance between $\mathrm{p} 53$ protein expression and TP53 mutations was assessed by the use of Cohen's Kappa measure of agreement.
The primary endpoint was disease-free survival (DFS), measured from the date of diagnosis until verified disease progression, death or last contact. Only DFS was analyzed for the entire early BC cohort, since follow-up for HE10/08 was still very short. Kaplan-Meier curves and log-rank tests were used for comparing time-to-event distributions, estimated by the product limit method, and evaluating DFS differences. Univariate Cox regression analysis was used for reporting hazard ratios. Univariate Cox with interactions was used for predictive analysis; treatment with trastuzumab was based on the local assessment, thus both TP53 mutations and p53 protein expression were tested for interactions with trastuzumab treatment in centrally assessed HER2-positive patients. Such patients with locally HER2-negative and centrally HER2-positive tumors were not treated with trastuzumab and were therefore used as untreated controls for the predictive analyses. Survival status was updated in June 2014.

For outcome analyses, tumor subtypes classified upon local testing and concordant tumor subtypes, i.e., locally and centrally classified at the same positive/ negative status, were examined. Multivariate analysis was conducted by local subtypes (HER2-positive in the pre-trastuzumab era, HER2-positive in the posttrastuzumab era, Luminal $\mathrm{A} / \mathrm{B}, \mathrm{TNBC}$ ) in the entire cohort, as well as in the concordant cases. Local subtypes were evaluated because additional treatment (hormone therapy or trastuzumab) was based on this classification. Concordant subtypes were used in order to further validate significant marker effects on outcome.

The models applied for multivariate analyses are shown in Supplementary File S1, Part C. The clinicopathological parameters were chosen by backward elimination among the ones included in each model. The statistically significant interactions from the predictive analysis were also examined upon adjustment for clinicopathological parameters.

All univariate tests were two-sided, with the significance level at $\alpha=0.05$. Significance threshold for keeping a variable in the multivariate models was set at $\alpha=0.15$, a level higher than usual in order to control for bias in the estimations. Due to the exploratory nature of the study, no correction for multiple testing was made.

The analysis was fully compliant with the reporting recommendations for tumor marker prognostic studies [73]. The SAS software was used for statistical analysis (SAS for Windows, version 9.3, SAS Institute Inc., Cary, $\mathrm{NC})$.

\section{Patient cohorts}

As described above, 1766 patients were eligible for the analysis out of a total of 3491 cases in the four trials; 1585 patients out of 1766 were informative for p53 protein expression. In both cases patients were 
not selected as representative cases, but based on the availability of tissue samples. Therefore, in order to identify whether the patients eligible for analysis differed from the starting cohorts in each case, with respect to clinicopathological parameters, multivariate logistic regression was used for modeling selection probability. Regarding differences between the 1766 patients and the total cohort $(n=3491)$, the analysis cohort included more patients with high Ki67 labeling, tumor size $>2 \mathrm{~cm}$, lower number of positive nodes, ER/ PgR positivity (central assessment) and patients who had received adjuvant radiotherapy (Table S12). Thus, we controlled for differences between selected and original cohorts, by using those parameters as adjustment factors in the multivariate models. The informative cases for p53 protein expression, compared to the analysis cohort, comprised of more patients with high values in CEN17 and Ki67, as well as with histological grade III (Table S13).

\section{ACKNOWLEDGMENTS}

The authors wish to thank Ms Emily Daskalaki for excellent technical assistance with NGS; Ms Elpida Charalambous, MSc, for NGS library construction; Ms Sofia Chrisafi, MSc for performing IHC; and Ms Helen Sgouramalli, MSc for block sectioning. Part of this work was presented at 2015 ASCO Annual Meeting.

\section{FUNDING}

This study was supported by an internal Hellenic Cooperative Oncology Group (HeCOG) translational research grant (HE TRANS_BR). The funders played no role in study design, data collection and analysis, decision to publish, or preparation of the manuscript.

This study was also partly supported by the Greek General Secretary for Research and Technology (GSRT) Program, Research in Excellence II, funded by $75 \%$ from the European Union and the Operational Program "Education \& Lifelong Learning" ESPA-THALIS\#266 of the Ministry of Education, Lifelong Learning \& Religious Affairs.

\section{CONFLICTS OF INTEREST}

None.

\section{REFERENCES}

1. Torre LA, Bray F, Siegel RL, Ferlay J, Lortet-Tieulent J, Jemal A. Global cancer statistics, 2012. CA. 2015; 65: 87-108.

2. Siegel RL, Miller KD, Jemal A. Cancer statistics, 2015. CA. 2015; 65:5-29.
3. Perou CM, Sorlie T, Eisen MB, van de Rijn M, Jeffrey SS, Rees CA, Pollack JR, Ross DT, Johnsen H, Akslen LA, Fluge O, Pergamenschikov A, Williams C, et al. Molecular portraits of human breast tumours. Nature. 2000; 406:747-752.

4. Sorlie T, Perou CM, Tibshirani R, Aas T, Geisler S, Johnsen $H$, Hastie $T$, Eisen MB, van de Rijn M, Jeffrey SS, Thorsen T, Quist H, Matese JC, et al. Gene expression patterns of breast carcinomas distinguish tumor subclasses with clinical implications. Proc Nat Acad Sci U S A. 2001; 98:10869-10874.

5. Sotiriou C, Neo SY, McShane LM, Korn EL, Long PM, Jazaeri A, Martiat P, Fox SB, Harris AL, Liu ET. Breast cancer classification and prognosis based on gene expression profiles from a population-based study. Proc Nat Acad Sci U S A. 2003; 100:10393-10398.

6. Eroles P, Bosch A, Perez-Fidalgo JA, Lluch A. Molecular biology in breast cancer: intrinsic subtypes and signaling pathways. Treat Rev. 2012; 38:698-707.

7. Gray J, Druker B. Genomics: the breast cancer landscape. Nature. 2012; 486:328-329.

8. Ding L, Raphael BJ, Chen F, Wendl MC. Advances for studying clonal evolution in cancer. Cancer letters. 2013; 340:212-219.

9. Hansen AR, Bedard PL. Clinical application of highthroughput genomic technologies for treatment selection in breast cancer. Breast Cancer Res. 2013; 15:R97.

10. Comprehensive molecular portraits of human breast tumours. The Cancer Genome Atlas Network. Nature. 2012; 490:61-70.

11. Stephens PJ, Tarpey PS, Davies H, Van Loo P, Greenman C, Wedge DC, Nik-Zainal S, Martin S, Varela I, Bignell GR, Yates LR, Papaemmanuil E, Beare D, et al. The landscape of cancer genes and mutational processes in breast cancer. Nature. 2012; 486:400-404.

12. Varna M, Bousquet G, Plassa LF, Bertheau P, Janin A. TP53 status and response to treatment in breast cancers. J Biomed Biotechnol. 2011; 2011:284584.

13. Olivier M, Langerod A, Carrieri P, Bergh J, Klaar S, Eyfjord J, Theillet C, Rodriguez C, Lidereau R, Bieche I, Varley J, Bignon Y, Uhrhammer N, et al. The clinical value of somatic TP53 gene mutations in 1,794 patients with breast cancer. Clin Cancer Res. 2006; 12:1157-1167.

14. Berge EO, Huun J, Lillehaug JR, Lonning PE, Knappskog S. Functional characterisation of p53 mutants identified in breast cancers with suboptimal responses to anthracyclines or mitomycin. Biochim Biophys Acta. 2013; 1830:2790-2797.

15. Silwal-Pandit L, Vollan HK, Chin SF, Rueda OM, McKinney S, Osako T, Quigley DA, Kristensen VN, Aparicio S, Borresen-Dale AL, Caldas C, Langerod A. TP53 mutation spectrum in breast cancer is subtype specific and has distinct prognostic relevance. Clin Cancer Res. 2014; 20:3569-3580. 
16. Joerger AC, Fersht AR. The tumor suppressor p53: from structures to drug discovery. Cold Spring Harbor perspectives in biology. 2010; 2:a000919.

17. Petitjean A, Mathe E, Kato S, Ishioka C, Tavtigian SV, Hainaut P, Olivier M. Impact of mutant p53 functional properties on TP53 mutation patterns and tumor phenotype: lessons from recent developments in the IARC TP53 database. Hum Mutat. 2007; 28:622-629.

18. Petitjean A, Achatz MI, Borresen-Dale AL, Hainaut P, Olivier M. TP53 mutations in human cancers: functional selection and impact on cancer prognosis and outcomes. Oncogene. 2007; 26:2157-2165.

19. Blagosklonny MV. p53 from complexity to simplicity: mutant p53 stabilization, gain-of-function, and dominantnegative effect. FASEB journal. 2000; 14:1901-1907.

20. Oren M, Maltzman W, Levine AJ. Post-translational regulation of the $54 \mathrm{~K}$ cellular tumor antigen in normal and transformed cells. Mol Cell Bio. 1981; 1:101-110.

21. George B, Datar RH, Wu L, Cai J, Patten N, Beil SJ, Groshen S, Stein J, Skinner D, Jones PA, Cote RJ. p53 gene and protein status: the role of p53 alterations in predicting outcome in patients with bladder cancer. J Clin Oncol. 2007; 25:5352-5358.

22. Kandioler D, Zwrtek R, Ludwig C, Janschek E, Ploner M, Hofbauer F, Kuhrer I, Kappel S, Wrba F, Horvath M, Karner J, Renner K, Bergmann M, et al. TP53 genotype but not p53 immunohistochemical result predicts response to preoperative short-term radiotherapy in rectal cancer. Ann Surg. 2002; 235:493-498.

23. Allred DC, Clark GM, Elledge R, Fuqua SA, Brown RW, Chamness GC, Osborne CK, McGuire WL. Association of $\mathrm{p} 53$ protein expression with tumor cell proliferation rate and clinical outcome in node-negative breast cancer. J Nat Cancer Inst. 1993; 85:200-206.

24. Yamamoto M, Hosoda M, Nakano K, Jia S, Hatanaka KC, Takakuwa E, Hatanaka Y, Matsuno Y, Yamashita H. p53 accumulation is a strong predictor of recurrence in estrogen receptor-positive breast cancer patients treated with aromatase inhibitors. Cancer science. 2014; 105:8188 .

25. Lara JF, Thor AD, Dressler LG, Broadwater G, Bleiweiss IJ, Edgerton S, Cowan D, Goldstein LJ, Martino S, Ingle JN, Henderson IC, Norton L, Winer EP, et al. p53 Expression in node-positive breast cancer patients: results from the Cancer and Leukemia Group B 9344 Trial (159905). Clin Cancer Res. 2011; 17:5170-5178.

26. Lee JW, Soung YH, Kim SY, Lee HW, Park WS, Nam SW, Kim SH, Lee JY, Yoo NJ, Lee SH. PIK3CA gene is frequently mutated in breast carcinomas and hepatocellular carcinomas. Oncogene. 2005; 24: 1477-1480.
27. Samuels Y, Wang Z, Bardelli A, Silliman N, Ptak J, Szabo S, Yan H, Gazdar A, Powell SM, Riggins GJ, Willson JK, Markowitz S, Kinzler KW, et al. High frequency of mutations of the PIK3CA gene in human cancers. Science. 2004; 304:554.

28. Cizkova M, Susini A, Vacher S, Cizeron-Clairac G, Andrieu C, Driouch K, Fourme E, Lidereau R, Bieche I. PIK3CA mutation impact on survival in breast cancer patients and in ERalpha, PR and ERBB2-based subgroups. Breast Cancer Res. 2012; 14:R28.

29. Kalinsky K, Jacks LM, Heguy A, Patil S, Drobnjak M, Bhanot UK, Hedvat CV, Traina TA, Solit D, Gerald W, Moynahan ME. PIK3CA mutation associates with improved outcome in breast cancer. Clin Cancer Res. 2009; 15:5049-5059.

30. Shah SP, Roth A, Goya R, Oloumi A, Ha G, Zhao Y, Turashvili G, Ding J, Tse K, Haffari G, Bashashati A, Prentice LM, Khattra J, et al. The clonal and mutational evolution spectrum of primary triple-negative breast cancers. Nature. 2012; 486:395-399.

31. Cheang MC, Martin M, Nielsen TO, Prat A, Voduc D, Rodriguez-Lescure A, Ruiz A, Chia S, Shepherd L, RuizBorrego M, Calvo L, Alba E, Carrasco E, et al. Defining breast cancer intrinsic subtypes by quantitative receptor expression. Oncologist. 2015; 20:474-482.

32. Fountzilas G, Skarlos D, Dafni U, Gogas H, Briasoulis E, Pectasides D, Papadimitriou C, Markopoulos C, Polychronis A, Kalofonos HP, Siafaka V, Kosmidis P, Timotheadou E, et al. Postoperative dose-dense sequential chemotherapy with epirubicin, followed by CMF with or without paclitaxel, in patients with highrisk operable breast cancer: a randomized phase III study conducted by the Hellenic Cooperative Oncology Group. Ann Oncology. 2005; 16:1762-1771.

33. Gogas H, Dafni U, Karina M, Papadimitriou C, Batistatou A, Bobos M, Kalofonos HP, Eleftheraki AG, Timotheadou E, Bafaloukos D, Christodoulou C, Markopoulos C, Briasoulis E, et al. Postoperative dosedense sequential versus concomitant administration of epirubicin and paclitaxel in patients with node-positive breast cancer: 5-year results of the Hellenic Cooperative Oncology Group HE 10/00 phase III Trial. Breast Cancer Res Treat. 2012; 132:609-619.

34. Fountzilas G, Dafni U, Papadimitriou C, Timotheadou E, Gogas H, Eleftheraki AG, Xanthakis I, Christodoulou C, Koutras A, Papandreou CN, Papakostas P, Miliaras S, Markopoulos C, et al. Dose-dense sequential adjuvant chemotherapy followed, as indicated, by trastuzumab for one year in patients with early breast cancer: first report at 5-year median follow-up of a Hellenic Cooperative Oncology Group randomized phase III trial. BMC cancer. 2014; 14:515. 
35. Walerych D, Napoli M, Collavin L, Del Sal G. The rebel angel: mutant p53 as the driving oncogene in breast cancer. Carcinogenesis. 2012; 33:2007-2017.

36. Loi S, Michiels S, Lambrechts D, Fumagalli D, Claes B, Kellokumpu-Lehtinen PL, Bono P, Kataja V, Piccart MJ, Joensuu H, Sotiriou C. Somatic mutation profiling and associations with prognosis and trastuzumab benefit in early breast cancer. J Nat Cancer Inst. 2013; 105: 960-967.

37. Zardavas D, Phillips WA, Loi S. PIK3CA mutations in breast cancer: reconciling findings from preclinical and clinical data. Breast Cancer Res. 2014; 16:201.

38. Neilsen PM, Noll JE, Suetani RJ, Schulz RB, Al-Ejeh F, Evdokiou A, Lane DP, Callen DF. Mutant p53 uses p63 as a molecular chaperone to alter gene expression and induce a pro-invasive secretome. Oncotarget. 2011; 2:1203-1217. doi: 10.18632/oncotarget.382.

39. Berns EM, van Staveren IL, Look MP, Smid M, Klijn JG, Foekens JA. Mutations in residues of TP53 that directly contact DNA predict poor outcome in human primary breast cancer. Br J Cancer. 1998; 77:1130-1136.

40. Sato K, Hara T, Ohya M. The code structure of the p53 DNA-binding domain and the prognosis of breast cancer patients. Bioinformatics. 2013; 29:2822-2825.

41. Hill KA, Sommer SS. p53 as a mutagen test in breast cancer. Environ Mol Mutagen. 2002; 39:216-227.

42. Olivier M, Hainaut P. TP53 mutation patterns in breast cancers: searching for clues of environmental carcinogenesis. Semin Cancer Biol. 2001; 11:353-360.

43. Curtis C, Shah SP, Chin SF, Turashvili G, Rueda OM, Dunning MJ, Speed D, Lynch AG, Samarajiwa S, Yuan Y, Graf S, Ha G, Haffari G, et al. The genomic and transcriptomic architecture of 2,000 breast tumours reveals novel subgroups. Nature. 2012; 486:346-352.

44. Bastien RR, Rodriguez-Lescure A, Ebbert MT, Prat A, Munarriz B, Rowe L, Miller P, Ruiz-Borrego M, Anderson D, Lyons B, Alvarez I, Dowell T, Wall D, et al. PAM50 breast cancer subtyping by RT-qPCR and concordance with standard clinical molecular markers. BMC Med Genomics. 2012; 5:44.

45. Bertheau P, Turpin E, Rickman DS, Espie M, de Reynies A, Feugeas JP, Plassa LF, Soliman H, Varna M, de Roquancourt A, Lehmann-Che J, Beuzard Y, Marty M, et al. Exquisite sensitivity of TP53 mutant and basal breast cancers to a dose-dense epirubicincyclophosphamide regimen. PLoS medicine. 2007; 4:e90.

46. Varna M, Lehmann-Che J, Turpin E, Marangoni E, ElBouchtaoui M, Jeanne M, Grigoriu C, Ratajczak P, Leboeuf C, Plassa LF, Ferreira I, Poupon MF, Janin A, et al. p53 dependent cell-cycle arrest triggered by chemotherapy in xenografted breast tumors. Int J Cancer. 2009; 124:991-997.

47. Aas T, Borresen AL, Geisler S, Smith-Sorensen B, Johnsen H, Varhaug JE, Akslen LA, Lonning PE. Specific
P53 mutations are associated with de novo resistance to doxorubicin in breast cancer patients. Nat Med. 1996; 2:811-814.

48. Borresen AL, Andersen TI, Eyfjord JE, Cornelis RS, Thorlacius S, Borg A, Johansson U, Theillet C, Scherneck S, Hartman S, et al. TP53 mutations and breast cancer prognosis: particularly poor survival rates for cases with mutations in the zinc-binding domains. Genes, Chromosomes Cancer. 1995; 14:71-75.

49. Geisler S, Lonning PE, Aas T, Johnsen H, Fluge O, Haugen DF, Lillehaug JR, Akslen LA, BorresenDale AL. Influence of TP53 gene alterations and c-erbB-2 expression on the response to treatment with doxorubicin in locally advanced breast cancer. Cancer Resh. 2001; 61: 2505-2512.

50. Bayraktar S, Royce M, Stork-Sloots L, de Snoo F, Gluck S. Molecular subtyping predicts pathologic tumor response in early-stage breast cancer treated with neoadjuvant docetaxel plus capecitabine with or without trastuzumab chemotherapy. Med Oncol. 2014; 31:163.

51. Gluck S, Ross JS, Royce M, McKenna EF, Jr, Perou CM, Avisar E, Wu L. TP53 genomics predict higher clinical and pathologic tumor response in operable early-stage breast cancer treated with docetaxel-capecitabine +/trastuzumab. Breast Cancer Res Treat. 2012; 132:781791.

52. Hoadley KAB WTP, B.N. Mutational analysis of CALGB 40601 (Alliance), a neoadjuvant phase III trial of weekly paclitaxel $(\mathrm{T})$ and trastuzumab $(\mathrm{H})$ with or without lapatinib (L) for HER2- positive breast cancer. 2014; S3-06.

53. Berns K, Horlings HM, Hennessy BT, Madiredjo M, Hijmans EM, Beelen K, Linn SC, Gonzalez-Angulo AM, Stemke-Hale K, Hauptmann M, Beijersbergen RL, Mills GB, van de Vijver MJ, et al. A functional genetic approach identifies the PI3K pathway as a major determinant of trastuzumab resistance in breast cancer. Cancer cell. 2007; 12:395-402.

54. Kataoka Y, Mukohara T, Shimada H, Saijo N, Hirai M, Minami H. Association between gain-of-function mutations in PIK3CA and resistance to HER2-targeted agents in HER2-amplified breast cancer cell lines. Ann Oncol. 2010; 21:255-262.

55. Moasser MM. Two dimensions in targeting HER2. J Clin Oncol. 2014; 32:2074-2077.

56. Joensuu H, Kellokumpu-Lehtinen PL, Bono P, Alanko T, Kataja V, Asola R, Utriainen T, Kokko R, Hemminki A, Tarkkanen M, Turpeenniemi-Hujanen T, Jyrkkio S, Flander M, et al. Adjuvant docetaxel or vinorelbine with or without trastuzumab for breast cancer. N Enlg J Med. 2006; 354:809-820.

57. Romond EH, Perez EA, Bryant J, Suman VJ, Geyer CE Jr, Davidson NE, Tan-Chiu E, Martino S, Paik S, Kaufman PA, Swain SM, Pisansky TM, Fehrenbacher L, 
et al. Trastuzumab plus adjuvant chemotherapy for operable HER2-positive breast cancer. N Enlg J Med. 2005; 353:1673-1684.

58. Pogue-Geile KL, Song N, Jeong JH, Gavin PG, Kim SR, Blackmon NL, Finnigan M, Rastogi P, Fehrenbacher L, Mamounas EP, Swain SM, Wickerham DL, Geyer CE, et al. Intrinsic subtypes, PIK3CA mutation, and the degree of benefit from adjuvant trastuzumab in the NSABP B-31 trial. J Clin Oncol. 2015; 33:1340-1347.

59. Cizkova M, Dujaric ME, Lehmann-Che J, Scott V, Tembo O, Asselain B, Pierga JY, Marty M, de Cremoux P, Spyratos F, Bieche I. Outcome impact of PIK3CA mutations in HER2-positive breast cancer patients treated with trastuzumab. Br J Cancer. 2013; 108: 1807-1809.

60. Gianni L, Dafni U, Gelber RD, Azambuja E, Muehlbauer S, Goldhirsch A, Untch M, Smith I, Baselga J, Jackisch C, Cameron D, Mano M, Pedrini JL, et al. Treatment with trastuzumab for 1 year after adjuvant chemotherapy in patients with HER2-positive early breast cancer: a 4-year follow-up of a randomised controlled trial. Lancet Oncology. 2011; 12:236-244.

61. Guarneri V, Dieci MV, Frassoldati A, Maiorana A, Ficarra G, Bettelli S, Tagliafico E, Bicciato S, Generali DG, Cagossi K, Bisagni G, Sarti S, Musolino A, et al. Prospective Biomarker Analysis of the Randomized CHER-LOB Study Evaluating the Dual Anti-HER2 Treatment With Trastuzumab and Lapatinib Plus Chemotherapy as Neoadjuvant Therapy for HER2Positive Breast Cancer. Oncologist. 2015; 20:1001-1010.

62. Loibl S, von Minckwitz G, Schneeweiss A, Paepke S, Lehmann A, Rezai M, Zahm DM, Sinn P, Khandan F, Eidtmann H, Dohnal K, Heinrichs C, Huober J, et al. PIK3CA mutations are associated with lower rates of pathologic complete response to anti-human epidermal growth factor receptor 2 (her2) therapy in primary HER2-overexpressing breast cancer. J Clin Oncol. 2014; 32:3212-3220.

63. Majewski IJ, Nuciforo P, Mittempergher L, Bosma AJ, Eidtmann H, Holmes E, Sotiriou C, Fumagalli D, Jimenez J, Aura C, Prudkin L, Diaz-Delgado MC, de la Pena L, et al. PIK3CA mutations are associated with decreased benefit to neoadjuvant human epidermal growth factor receptor 2-targeted therapies in breast cancer. J Clin Oncol. 2015; 33:1334-1339.

64. Fountzilas G, Dafni U, Bobos M, Batistatou A, Kotoula V, Trihia H, Malamou-Mitsi V, Miliaras S, Chrisafi S, Papadopoulos S, Sotiropoulou M, Filippidis T, Gogas H, et al. Differential response of immunohistochemically defined breast cancer subtypes to anthracycline-based adjuvant chemotherapy with or without paclitaxel. PloS one. 2012; 7:e37946.

65. Badve S, Dabbs DJ, Schnitt SJ, Baehner FL, Decker T, Eusebi V, Fox SB, Ichihara S, Jacquemier J, Lakhani SR, Palacios J, Rakha EA, Richardson AL, et al. Basal-like and triple-negative breast cancers: a critical review with an emphasis on the implications for pathologists and oncologists. Mod Pathol. 2011; 24:157-167.

66. Kotoula V, Charalambous E, Biesmans B, Malousi A, Vrettou E, Fountzilas G, Karkavelas G. Targeted KRAS mutation assessment on patient tumor histologic material in real time diagnostics. PloS one. 2009; 4:e7746.

67. Kotoula V, Lyberopoulou A, Papadopoulou K, Charalambous E, Alexopoulou Z, Gakou C, Lakis S, Tsolaki E, Lilakos K, Fountzilas G. Evaluation of two highly-multiplexed custom panels for massively parallel semiconductor sequencing on paraffin DNA. PloS one. 2015; 10:e 0128818.

68. Soussi T, Wiman KG. TP53: an oncogene in disguise. Cell Death Differ. 2015; 22:1239-1249.

69. Thusberg J, Olatubosun A, Vihinen M. Performance of mutation pathogenicity prediction methods on missense variants. Hum Mutat. 2011; 32:358-368.

70. Martelotto LG, Ng CK, De Filippo MR, Zhang Y, Piscuoglio S, Lim RS, Shen R, Norton L, Reis-Filho JS, Weigelt B. Benchmarking mutation effect prediction algorithms using functionally validated cancer-related missense mutations. Genome Biol. 2014; 15:484.

71. Papaxoinis G, Kotoula V, Alexopoulou Z, Kalogeras KT, Zagouri F, Timotheadou E, Gogas H, Pentheroudakis G, Christodoulou C, Koutras A, Bafaloukos D, Aravantinos G, Papakostas P, et al. Significance of PIK3CA Mutations in Patients with Early Breast Cancer Treated with Adjuvant Chemotherapy: A Hellenic Cooperative Oncology Group (HeCOG) Study. PloS one. 2015; 10:e0140293.

72. Thor AD, Berry DA, Budman DR, Muss HB, Kute T, Henderson IC, Barcos M, Cirrincione C, Edgerton S, Allred C, Norton L, Liu ET. erbB-2, p53, and efficacy of adjuvant therapy in lymph node-positive breast cancer. $\mathrm{J}$ Nat Cancer Inst. 1998; 90:1346-1360.

73. McShane LM, Hayes DF. Publication of tumor marker research results: the necessity for complete and transparent reporting. J Clin Oncol. 2012; 30: 4223-4232. 